\title{
Marketing and Making Carbon Dumps: Commodification, Calculation and Counterfactuals in Climate Change Mitigation
}

\author{
LARRY LOHMANN \\ The Corner House, Dorset, UK
}

\section{Introduction}

The climate change crisis is an example of a familiar problem of techno-politics- the overflowing waste dump. For over 150 years, industrial societies have been transferring fossil carbon from underground deposits of coal, oil and gas, via the combustion chamber, to a more active and rapidly circulating carbon pool, or 'dump', in the air, oceans, vegetation and soil. Some of the fossil carbon being added to this active pool builds up in the atmosphere, at a current rate of around six extra billion tonnes of carbon dioxide every year. This overflow cannot go on indefinitely. If all the remaining fossil carbon were taken out of the ground and injected into the carbon pool on or near the surface, the earth would probably become uninhabitable (Leggett, 1999).

Historically, global carbon-cycling capacity has been open to use by all, with no rules or laws applied except ones relating to pollutants that may accompany carbon dioxide. However, concern has grown that this capacity is both overused and unequally used. Industrialized countries alone currently use far more of the absorptive capacity of the biosphere and atmosphere to stow their carbon emissions in than is 'available', with the Intergovernmental Panel on Climate Change (IPCC) famously stating that 60-80\% cuts in fossil fuel emissions will be necessary in order to stabilize atmospheric concentrations of carbon dioxide (IPCC, 1990). Pointing out that the 'largest share of historical and current emissions of greenhouse gases has originated in developed countries', the UN Framework Convention on Climate Change (UNFCCC) insists that North and South have 'differentiated responsibilities' for dealing with the problem (UNFCCC, 1992).

The 1997 Kyoto Protocol of the UNFCCC, which took effect on 16 February 2005, duly gestures toward both emissions reductions and equity. It mandates that industrialized country signatories freeze their emissions at an average of around 5\% below 1990

Correspondence Address: Larry Lohmann, The Corner House, Station Road, Sturminster Newton, Dorset DT10 1YJ, UK. Email: larrylohmann@gn.apc.org 
levels. At the same time, it allows Southern nations, for the time being, to continue to enjoy unconstrained access to the world carbon dump.

The most striking thing about the Protocol, however, is that it attempts to set up a market in carbon dumps as a main coordinating mechanism. While the implications of this peculiar, centralizing and quantification-heavy choice for the structure and fate of the science, politics and technology of climate change mitigation are enormous, their full extent is only now beginning to be recognized. Among most observers, Kyoto is still seen as a harmless, neutral stopgap measure pending more serious efforts to address climate change-disappointingly feeble, perhaps, but a necessary way station that at least leaves all important future options open. A casual Google search using the conjunction of 'Kyoto Protocol' and 'first step' turns up 90,000 entries emanating from sources as diverse as politicians, journalists, environmentalists and UN officials. Whether it is 'a crucial first step', 'an important first step', 'a significant first step', 'a step in the right direction', 'a nice first step', 'a modest first step', 'a very small first step', a 'tiny first step' or 'an imperfect first step', this ubiquitous linear metaphor presents the Protocol as straddling all paths into the future of climate politics. 'Kyoto is the only game in town', a recent editorial has it (Bangkok Post, 24 February 2005).

This article suggests reasons to be sceptical of such claims. Deploying insights developed in science and technology studies, it argues that the scale and contradictions of the work needed to build the carbon market to which the Kyoto Protocol has committed its ratifiers have been greatly underestimated, and that the debate about climate action needs to be broadened.

After introducing Kyoto's prehistory and proposed market structure, as well as some theoretical concepts, this article probes the difficulties and conflicts involved in creating the agents and property rights that the market requires. It then surveys some of the ways ongoing attempts to frame a carbon dump commodity are shaping the science and technology of climate change mitigation, and the techno-political contradictions that are developing as a result. Along the way, the article suggests ways in which grassroots resistance to new carbon dump projects is linked to the tendency of Kyoto-style carbon accounting systems to marginalize non-corporate, non-state and non-expert contributions toward climatic stability. The Kyoto Protocol's market system, the article argues, not only cannot succeed in slowing the upward flow of fossil carbon into the overflowing above-ground carbon dump, but is also entrenching institutions and procedures that are likely to stand in the way of constructive approaches to climate change.

\section{Rise of a Market Approach}

In the early 1990s, parties to the UNFCCC had dozens of approaches to choose from for reducing flows of fossil carbon into the above-ground dump. One was to begin phasing out national and international subsidies and military backing for fossil fuel extraction, while subsidizing energy conservation and non-carbon energy and supporting local movements against fossil fuel extraction, fossil-dependent industries, airport expansion and so forth. Another was to develop or revive low- or non-carbon technologies on a regional basis, reversing trends of declining research and development into non-nuclear, non-carbon energy alternatives, with an eye ultimately to gaining competitive advantage over remaining heavily fossil-dependent corporate structures. Still another was to institute dump-use taxes, possibly combined with reparations to be paid by past over-users to under-users. A further option was to assign a restricted amount of nontradable property in the global 
carbon dump to each country, instituting penalties for dump theft. A fifth approach was to auction space in the global carbon dump to private owners. A sixth was to create a trust to sell rights in the dump to polluters and distribute revenue to communities or individuals. And so on.

The Kyoto Protocol's framers passed over these possibilities and others. Instead they undertook to translate public concern about climate change into greenhouse gas emissions permit and credit prices. The earth's carbon dump would gradually be made economically scarce through limits on its use imposed by states. A market would be built for the new resource by creating and distributing tradable legal rights to it. Bargaining would then generate a price that would reflect the value society placed on carbon dump use and 'denote the financial reward paid to reduce ... emissions'. Emitters who found ways of using the dump more efficiently could profit by selling their unused rights in it to more backward producers. Emitters could also develop new dumps. The market would 'help society find and move along the least-cost pollution-reduction supply curve' (Sandor et al., 2002, p. 57).

As the former Executive Secretary of the UNFCCC has recently noted, this approach was 'made in the USA' (Zammit Cutajar, 2004). Pressure from the Clinton government set in motion a politics which eventually prevailed over European and Southern objections to carbon dump trading (Grubb et al., 1999). Also significant was support from some Northern corporations for a scheme that, unlike taxation and auctioning, distributed free property rights in a hitherto 'open access' global dump to Northern countries, roughly in proportion to how much they were already (over)using it. Traders and bankers hoped to set up new carbon exchanges in London, Chicago, Sydney, Amsterdam, Leipzig and elsewhere. Environmental groups, too, threw in their lot with the tradable permits approach on the theory that it was the only way to get a climate treaty approved (Vedantam, 2005).

By the time the second George Bush pulled out of Kyoto in 2001 (much to the consternation of US companies hoping to profit from the carbon trade, such as Enron), the approach had become internationally entrenched even though much of its original political raison d'etre had vanished. Its environmentalist backers were left in the odd position of having to champion an agreement written largely by the US for US purposes on the basis of US experience and US economic thinking, but which no longer had US support. But the anomaly was quickly forgotten. Journalists and environmentalists alike soon came to treat any criticism of the treaty not as directed against US-style 'free market' environmentalism but, ironically, as playing into the hands of US oil interests and as endorsing a do-nothing position.

Behind the US push for a tradable permits framework for Kyoto lay a complicated political and intellectual history-now also mostly lost to environmentalist consciousness. One aspect of this history was a controversial tradition in economics theorized in the mid-twentieth century work of Ronald Coase $(1960,1988)$. Coase believed that it was an anachronism, and irrational, to treat pollution as an externality that could only be internalized through regulation or taxation, or as something for which one could be liable for damages or which had to be reduced whatever the cost. To do so, he thought, would be to fail to 'optimize' pollution so that it maximized overall social welfare. Like many economists, Coase tended to identify this welfare with 'total product' - a foreshortened and unstable object synthesized through commensurating and reconceptualizing goods and harms.

In this context, the rational approach to pollution was to integrate it into a market calculus by creating rights to pollute as tradable 'factors of production'. In a market without 
transaction costs and with perfect information, and inhabited by properly calculating, maximizing economic agents, these rights would automatically be bargained into the hands of those who could produce the most wealth from them, resulting in the greatest good for the greatest number. But since, as Coase stressed, such a market is only a figment of the imagination, in reality the state and the courts would have to lend a hand not only by creating these rights but also by pushing them in the direction of those who could make the most from them. In theory, Coase conceded, optimization of pollution could also be achieved through a tax that penalized losses to 'total product'. But he rejected such a tax as being impossible to calculate.

Coase's theory was modified by tradable environmental permit theorists (Dales, 1968; Hahn and Stavins, 1995; Barnes, 2001) and enriched by US experience with markets in allowances for the emission of sulphur dioxide and other pollutants (Ellerman et al., 2000, 2003). Like many other economic theories, the model echoed the Lockean claim that rights to property should go to those who could add the most exchange value to it, 'improve' it, or produce the most from it in commerce-a justification used beginning in the early seventeenth century for seizing land both from conquered peoples in the English colonies and from commoners in England itself (Wood, 2002). This view of property survives, in coded form, in the widespread but questionable beliefs that tradable permit systems such as Kyoto's are a 'lowercost', 'more efficient', 'more innovation-producing' or 'more growth-promoting' alternative to other forms of regulation or coordination (Cole, 2002; Driesen, 2003). The notion that progress in climate mitigation can be measured by calculating carbon efficiency per unit of Gross Domestic Product—commensurating climate stability with an abstract, aggregated economic good-belongs to the same family of ideas.

Bolstering Kyoto's tradable permit approach was the doctrine, again far more widespread in US culture than elsewhere, that when environmental goods are not privately owned and marketed, or have no price or a zero price, they will become degraded in the absence of draconian centralized government control. On this view, it is holders of private title to an environmental good who will always manage it best and with the least coercion involved (For contrary views, see Thompson, 1990; Buck, 1985; Polanyi, 2001; Acheson and McCay, 1990; IASCP, 2005; Illich, 1983; Bromley, 1991; Ostrom, 1990; Rose, 1999). In fact, the tradable permits solution is often considered both a market approach and a 'command and control' approach (Stewart, 1990), since not only the property rights, but also how scarce the commodity is, depend on government regulation (see 'Kyoto's First Prong', below).

\section{Kyoto Protocol}

The Kyoto Protocol that grew out of the history sketched above has two prongs. One, in effect, markets the world's existing carbon dumps. The other develops and markets new dumps.

\section{Kyoto's First Prong}

Under the first prong of the Protocol, the United Nations distributes tens of billions of dollars' worth of rights (Point Carbon, 16 February 2005) to (over)use the existing global carbon dump to 38 industrialized nations who, in per capita terms, already use it the most, permitting them to sell portions of what they don't use. In theory, the Protocol 
binds these countries to reducing their emissions by an average of about 5\% below 1990 levels by 2008-2012 (that is, to use no more than about $95 \%$ of the dump space they had used in 1990). Most nations receiving these rights are in turn passing large quantities of them on gratis to private companies in heavy industrial sectors.

Under the collective European Union Emissions Trading Scheme (EUETS), for example, rights to emit 2.2 billion tonnes of carbon dioxide yearly are being allocated to around 9,200 industrial installations across the EU, without much public discussion. The UK government alone plans to hand out, as of 2005, free, transferable global carbon dump assets currently worth around $€ 5$ billion yearly to approximately 1,000 installations responsible for around $46 \%$ of UK emissions (see Table 1). Grantees can then sell any unused rights on to other polluters.

These property rights are transferable, as with ordinary private property; temporary, as with leaseholds, concessions or patents; and assets that constitute a 'major input factor to production' (Fichtner et al., 2003, p. 257). UK power generators, for example, are expected to receive an annual $£ 500$ million windfall (House of Commons, 2005, p. 17) which they will then be 'able to convert ... into valuable income on their balance sheets' (Cameron, 2005, p. Ev130). Indeed, the EUETS, together with other components of the Kyoto package, presupposes one of the largest schemes for creating property rights in history and will be one component in what some believe may become the largest market ever created.

Table 1. Quasi-privatization of the existing global carbon dump by the UK (proposed national allocation under the EU Emissions Trading Scheme, 2005)

\begin{tabular}{lcccc}
\hline Industrial sector & $\begin{array}{c}\text { Annual gift } \\
\text { of emissions } \\
\text { rights }\left(\mathrm{mtCO}_{2} \text { ) }\right. \\
\text { (UK only) }\end{array}$ & $\begin{array}{c}\text { Increase/decrease } \\
\text { from actual } \\
\text { average emissions } \\
1998-2003\end{array}$ & $\begin{array}{c}\text { Fraction of } \\
\text { 'available' world } \\
\text { above-ground } \\
\text { carbon dump }\end{array}$ & $\begin{array}{c}\text { Approximate } \\
\text { current annual } \\
\text { value at } \\
€ 20 / \text { tCO }^{\mathrm{b}}\end{array}$ \\
\hline Power generators & 145.3 & $-6 \%$ & $1.5-3.0 \%$ & $€ 2.906 \mathrm{~b}$ \\
Iron and steel & 23.3 & $+16 \%$ & $0.2-0.5 \%$ & $466 \mathrm{~m}$ \\
Refineries & 19.8 & $+11 \%$ & $0.2-0.4 \%$ & $396 \mathrm{~m}$ \\
Offshore oil and gas & 19.1 & $+14 \%$ & $0.2-0.4 \%$ & $382 \mathrm{~m}$ \\
Cement & 10.7 & $+18 \%$ & $0.1-0.2 \%$ & $214 \mathrm{~m}$ \\
Chemicals & 10.1 & $+12 \%$ & $0.1-0.2 \%$ & $202 \mathrm{~m}$ \\
Pulp and paper & 4.7 & $+18 \%$ & $0.0-0.1 \%$ & $94 \mathrm{~m}$ \\
Food and drink & 3.9 & $+26 \%$ & $0.0-0.1 \%$ & $78 \mathrm{~m}$ \\
Other industries & 15.1 & $+16 \%$ & $0.2-0.3 \%$ & $302 \mathrm{~m}$ \\
Total & $\mathbf{2 5 2 . 0}$ & $\mathbf{+ 2 \%}$ & $\mathbf{2 . 6 - 5 . 1 \%}$ & $€ \mathbf{5 . 0 4 0 b}$ \\
\hline
\end{tabular}

aFigures in this column are not based on any attempt to estimate the earth's capacity to recycle transfers of fossil carbon with no remainder, which, even if initial assumptions could be agreed on, would probably be impossible in technical terms. Rather, it takes as point of reference the Intergovernmental Panel on Climate Change finding that anthropogenic $\mathrm{CO}_{2}$ emissions from fossil fuel combustion and flaring must be reduced by $60-80 \%$ from current levels of 24,533 million metric tonnes/year to achieve eventual stabilization of $\mathrm{CO}_{2}$ levels at twice Industrial Revolution levels.

${ }^{\mathrm{b}}$ Approximate price in early August 2005. Without structural innovation, higher prices will not necessarily result in impeding below-ground to above-ground carbon flows. By comparison, direct annual subsidies to fossil fuels are estimated at up to US $\$ 235$ billion (CDM Watch, 2004). For every tonne of uncompensated-for $\mathrm{CO}_{2}$ emitted above the limit, companies face a fine of $€ 40$, rising to $€ 100$ from 2008 onwards.

${ }^{\mathrm{c} C}$ Columns may not add up due to rounding.

Sources: DEFRA, 2005; Carbon Market News, 2 August 2005. 
At the same time, however, EUETS emissions rights are only partially exclusionary, differentiating them from ordinary private property. While neither under the EUETS nor under its parent Kyoto agreement are any tradable permits to be granted to Southern countries that have ratified the Protocol, neither are any restrictions being placed on Southern dump use. (The US, which refuses to ratify the Protocol, also continues to have free access to the dump although receiving no tradable rights to it.) Hence it is only other Northern ratifiers of the Kyoto Protocol and their corporations that are excluded from using the carbon dump assets which have been granted to UK firms through the EUETS. As is routinely observed, this lack of global exclusion, if maintained, would ultimately make Kyoto climatically ineffective.

In addition, the EUETS, together with the rest of the Kyoto market, is unlike other tradable permit systems, in which what is believed to be the 'core' of a non-renewable resource (such as a fishery) is deliberately preserved and rights given away only to extract and trade on the margins (Rose, 1999). Under Kyoto, none of the 'sustainable' core is set aside; instead, legal rights to several hundred per cent of it are immediately given away and become eligible for trade. For example, UK industrial sectors, with the exception of power generators, are to be granted formal rights to emit yearly between 2005 and 2007 at least as much as they annually emitted between 1998 and 2003-a level acknowledged to be unsustainable. While nations and corporations are expected to surrender these assets bit by bit over time-this is how emissions are to be cut-there has been no serious political analysis' (Rayner, 2005, p. Ev140) of the magnitude and pace of this dispossession, nor of how it is to be negotiated. Signs so far are not encouraging, with $\mathrm{CO}_{2}$ emissions of all but a few of Kyoto's parties increasing rather than decreasing (House of Commons, 2005, p. 25). Forcing the surrender of property rights was easier in the sulphur dioxide reduction programme in the US, partly because they had been legislated by a single state and parties could not withdraw.

\section{Kyoto's Second Prong}

Under the Kyoto Protocol's second prong, industrialized countries wanting to avoid restrictions on use of the existing world carbon dump are encouraged to locate, develop and purchase new, lower-cost dumps. Although schemes for establishing huge tree plantations to soak up industrial carbon dioxide emissions through photosynthesis have been mooted for nearly three decades (Dyson, 1977), the Protocol has gone further. In addition to encouraging industrializing countries to try to build new biological carbon dumps within their own borders, it set up two institutional mechanisms, the Clean Development Mechanism (CDM) and Joint Implementation (JI), to find or create internationally tradable 'equivalents' to the dump space that, among the 38 industrialized countries, was being quantified through legislation of a cap. These equivalents come in the form of a wide range of end-of-pipe, greenhouse-gas'saving' projects to generate credits for Northern countries or corporations to buy in lieu of reducing their own fossil fuel use. (Together with emissions trading, these are known as Kyoto's three 'flexible mechanisms'.) In anticipation of a market in fossil fuel-burning licenses from such projects, the private sector also began experimenting with them.

Two kinds of new carbon dump can be distinguished. The first is to be built from land, forests, soils, water, even parts of the oceans. Fast-growing eucalyptus monocultures, for 
example, may be established on cheap land in the South and the carbon they 'sequester' then sold; or carbon dioxide pumped into deep layers of the ocean or underground geological formations; or tilling halted in order to let carbon build up in soils; or oceans salted with iron to stimulate plant growth.

The second, more complex type of new dump, is, in a sense, carved out of the future of Southern and Eastern European countries. Fossil-fuel users in the North buy permission to go on dumping by investing in activities abroad which, while often contributing still more fossil carbon flows into the dumps, are claimed to produce smaller flows than would 'otherwise' be the case. (These projects include forestry projects carried out outside the North's emissions cap, so there is some overlap between the two kinds of carbon dump.) Alternative futures which would use even less carbon are dismissed by contracted experts.

Hence an electricity utility in the North can gain extra permits to burn fossil fuel in its own country by, for example, burning methane (a more potent greenhouse gas than carbon dioxide) in a Southern country-whether in a gas-fired power plant, a flaring tower on an oil field, or in a combustion chamber accepting waste gas from a landfill-if this burning can be demonstrated to release less $\mathrm{CO}_{2}$ equivalent than what would be released in its absence by a coal-burning plant, by non-flared gas, or by methane releases from rotting garbage. It does not matter that energy efficiency measures or solar power-or not building a plant at all-would be less carbon-intensive than methane combustion. As long as the company's consultants can rhetorically eliminate these possible other 'futures' in favour of the single counterfactual scenario represented by the coal-fired plant, it can be licensed to continue transfer of carbon to the atmosphere above its own power stations. The claim that alternative low-carbon or non-carbon futures do not exist becomes a way of dumping carbon in those futures.

Thus the carbon accounts of Nigeria, say, could show a debit for $\mathrm{CO}_{2}$ released by the gas flaring that the fossil export industry conducts within its borders, while the accounts of an industrialized country sponsoring the flaring technology could be credited for the climaticforcing difference between that flaring and the release of unburned methane. Today, large hydroelectric dams, efficiency programmes, forestry firms, biomass energy projects, wind farms and even coal mines and fossil-fuelled power plants are all seeking licenses to sell dumping rights on the ground that they emit less carbon than business-as-usual 'alternatives' identified by experts. Carbon project developers are also hoping to license further fossil emissions by capturing or destroying hydroflourocarbons such as HFC-23; burning off methane found in coal seams in China or generated by pig manure in Chile (Bloomberg News, 2004); feeding supplements to Ugandan cows to reduce their methane flatulence (Climate Neutral Network, 2000); rearranging the timing of traffic signals; and even cleaning up debris left by the Indian Ocean tsunami (Deepak Mawandia, 2005).

\section{Framing a Market: What Kyoto Had to Do}

\section{Framing and Disentanglement}

Market exchange becomes possible, as Michel Callon (1998a, 1998b, 1999) and colleagues have stressed, only through the bracketing of spaces for calculation and transaction. Exchange requires simplified, uncontroversial owners, products and modes of 
ownership, and accounting requires knowing both who is accountable and how and what to count and not to count. As Timothy Mitchell (2002, p. 290) puts it, markets 'would be impossible if people were made to account for every cost'.

In a car market, for example, everybody agrees that it is the car company that owns the product, and everybody can identify what that product is. The processes by which the boundaries of the owners of the product, as well as of the product itself, are created are 'black-boxed'. Any possible claims of partial ownership by workers or communities near sources of raw materials are set to one side in order to enable and constrain the market, as is resistance to pricing of those materials, over-reliance on kinship in negotiating deals, medieval notions of 'fair price', and so forth. Callon calls this process 'framing' [borrowing a metaphor from Goffman (1974)] or 'disentanglement' [borrowing another from anthropologist Nicholas Thomas (1991)], and also uses the terms 'cleansing', 'simplification', 'disconnection', and 'formatting'. 'Agents and goods involved in calculations', he says, 'must be disentangled and framed if calculations are to be performed and completed' (Callon, 1999, p. 186).

The incipient Kyoto market is a good example. For the 'externality' of global warming to be 'internalized', industrial greenhouse gas emissions first have to be quantified, verified, recorded and accounted for. Then, in an added move peculiar to Kyoto and other multi-tiered climate market schemes, these emissions have to be commensurated with existing biospheric carbon and with the 'carbon savings' of speculative carbon projects. Uniform standards have to be created for the resulting new hybrid commodity. Sellers and buyers have to be identified and isolated by simplifying attributions of causality or responsibility and developing instruments of ownership. The displacements and institutions needed for running the system-negotiating arenas, legal processes, communication mechanisms, measuring instruments, police-are formatted as 'transaction costs' (Coase, 1937), which are then minimized, and foundations laid for securities and commodities exchanges as well as futures and options markets.

This struggle to frame agents and commodities has led to the creation of thousands of new centres of calculation [to use Latour's useful term (1999)]. These centres are located mainly in corporations, government ministries, the UN, the World Bank, consultancies, trading firms, investment banks, commodity exchanges, national laboratories, research establishments, industry associations, law firms, policy think-tanks, industrial standardsetting bodies, non-government organizations, and university departments of economics, forestry, agriculture, biology, law, physics, geology and politics.

\section{Overflowing and Re-entanglement}

The flip side of framing or disentanglement is what Callon terms 'overflowing' or 'reentanglement'. As Mitchell (2002, p. 292) puts it, the 'conventions and powers that enable the completion of an exchange' cannot contain all the human and nonhuman forces and interactions that would make it incomplete. In fact, because it 'mobilizes or concerns objects or beings endowed with an irreducible autonomy', framing is itself a 'source of overflowing'; 'it is one and the same movement which causes calculative agencies to proliferate, while reinscribing them into spaces of noncalculability' (Callon, 1998a, p. 39). The 'constraints, understandings and powers that frame the economic act ... and thus make the economy possible, at the same time render it incomplete', to use Mitchell's words (2002, p. 291). Market agents and goods are always 'boundary 
objects' (Star and Griesemer, 1989) which, while partly resynthesized for a market, at the same time hang on to characteristics relating to other contexts.

Individuals formatted as the mute, maximizing bundles of preferences of economic theory, for instance, are constantly-fortunately for the market-reasserting themselves as persuasive negotiators with voices and relationships (McCloskey, 1998, pp. 95-97). Similarly, money, formatted as a unitary solvent of social ties, is, in the hands of its users, constantly fragmented into discrete, incommensurate categories-a process that turns out to be essential for accounting itself (Zelizer, 1997; Callon, 1998a). When markets and buyers are created for hitherto unmarketed environmental goods, by the same token, resistance to pricing has to be quarantined, yet incessantly breaks out of that quarantine. One small example is rebellions or 'gaming' by participants in contingent valuation interviews where subjects are asked their 'willingness to pay' for good health or unspoiled wetlands (Lohmann, 1998a; Burgess et al., 1998).

Framing institutions themselves cannot be distinguished from what they frame with any guarantee of stability. The border of a market is 'not a line on a map, but a horizon that at every point opens up into other territories' (Mitchell, 2002, p. 292). Frames for market negotiation are themselves negotiable; spaces of calculation and noncalculation cannot be organized in impervious spheres (cf. Walzer, 1983).

To vary the metaphor, to frame a new market, or disentangle its agents and goods, is to repress certain things which return in other forms. It is to enclose certain things some of whose full commodification could involve the 'demolition of society', necessitating counter-movements of social protection (Polanyi, 2001). It is to black-box items (Latour, 1999) which, with some effort, can again be made visible. It is to simplify phenomena in ways that often defeat the point of the simplification, in something like the sense James C. Scott (1999) explores in the related context of the state. It is to translate, creating meanings that serve as frameworks for negotiation but which themselves are indeterminate boundary objects that are the result of, and subject to, negotiation and dispute (Quine, 1960; Lohmann, 2000). It is to create the rule that, confronted with alien social practices, turns out not to contain its own interpretation (Wittgenstein, 1953; Collins, 1992). It is to perform a technical fix which may be intended as a machine for eliminating politics (Ferguson, 1990) but which in fact sets up a selfreplicating chain of new problems and new 'fixes' (Lohmann, 1998a, 1998b; Callon, 1998; Sampson and Lohmann, 2000). Framings are works 'of violence as well as theory' (Mitchell, 2002, p. 299), generating overflows in which physical or grassroots resistance is often not usefully distinguishable from 'conceptual confusions' requiring an endless, problematic cascade of ad hoc refigurations of science and technology.

In what Callon calls 'hot' situations, negotiations aimed at identifying overflows are incomplete or unachievable, interests are unstable, and the identity of actors is unclear, making framing impossible or premature. Although 'externalities are at the centre of public debates', conditions are not 'cool' enough for the spadework for commercial relations or Coasean negotiation to be done.

The incipient Kyoto climate market, this paper argues, is one such case. Attempts are being made to create 'legal instruments providing evidence of ownership' and 'uniform standards for a commodity or security' (Sandor et al., 2002, p. 58) without the necessary conditions being present, as they arguably were for the US sulphur dioxide market (Cole, 2002). The next section of this paper will take up various failed attempts to define both agents and goods under each prong of the Kyoto Protocol. 


\section{Failures of Framing}

\section{Failure to Frame Agents under Kyoto's First Prong}

The Kyoto Protocol's market for the world's existing carbon dump requires an 'accounting method to create a greenhouse gas inventory which also assigns responsibility for emissions' (Bastianoni, 2004, p. 254). Early on, parties to the UNFCCC and their technical advisers tried to format national 'geo-bodies' (Winichakul, 1994) as the relevant agents (UNFCCC, 1992; Houghton, 1996). Anything emitted on Mexico’s territory, say, would be considered to be emitted 'by Mexico'.

This seemingly neutral unit of analysis, however, has been persistently re-entangled in disputes over responsibility, history, politics and exploitation. Southern negotiators and others have argued that 'inventories should focus on the location of economic demand' for carbon-intensive practices 'rather than on the site of production' (Grubb et al., 1999, p. 98). Economists have asked why a country should be held responsible for the emissions of (for example) trucks crossing its territory, if it has neither produced nor will use the goods that they carry (Bastianoni, 2004, p. 254), or of factories producing goods none of which its citizens enjoy. Environmentalists have questioned whether entities called 'Russia' or 'the UK' should be credited with post-1990 emissions reductions that are in fact due to post-Soviet economic collapse or the anti-unionism of a former Prime Minister that caused coal to give way to less-polluting natural gas. Indigenous movements opposing oil drilling on their territories have urged that they, not their governments, are the agents who are reducing emissions (Oilwatch, 2000). Still others urge that colonial history and patterns of imposed development are relevant to negotiating who the agents are to be in the new carbon market.

Kyoto's attempt to frame historical use of the global carbon dump as the criterion for property holdings in it has also run into difficulties. Under the EUETS, UK industry alone is being granted monetizable access to between approximately 2.5 and $5 \%$ of what might be designated as the 'available' world carbon dump (the figure for the EU corporate sector as a whole comes to between 23 and 45\%) (see Table 1). UK population, by contrast, comes to only $1 \%$ of the world total. The dump space granted to the UK, moreover, does not fall, geographically or otherwise, under UK legal jurisdiction as conventionally understood, but is used by all of the earth's inhabitants. As a result, the legal rights handed out by Kyoto-related schemes have been subjected to anti-colonialist challenges calling for more egalitarian dispositions of property (Pearce, 2001; Agarwal et al., 1999) or domestic challenges that would recognize the competing property claims of individuals (Fleming, 2005). By handing out the most legal rights to the highest emitters, governments are also making themselves potentially liable to claims for damages caused by greenhouse gas emissions. New Southern entrants into Kyoto's emissions limitation framework are meanwhile likely to demand property rights that 'upset the historically established expectations of the industrialized world' (Rayner, 2005, p. Ev141).

The 'polluter earns' principle defining property owners in the EUETS market has also raised concern that fossil fuel-fired power generators are in line for 'competitive advantages ... which cannot be justified from a climate policy point of view' (Point Carbon, 15 February 2005) in the form of windfalls that are unlikely to be used for innovation or structural change in the energy economy (Rayner, 2005) and that governments may ultimately have to step in to prevent (Citigroup Smith Barney, 2003; ENDS, 2003a, 
2003b, 2004a, 2004b). One cement firm complains that large emitters are being given incentives not to close badly-polluting installations and invest in more efficient ones (vanderBorght, 2004/5). In the first public spot trade of EU allowances in February 2005, Danish power utility Energi E2 was able to sell a block of rights it had been granted free by its government to Shell simply because a spell of mild temperatures had happened to keep the utility's carbon emissions slightly below expected levels (Carbon Market Daily, 2005). The award of carbon credits to various EU energy and chemical corporations merely for having obeyed government regulations or received government subsidies has prompted protests and even legal action (Point Carbon, 16 November 2004).

Business itself remains confused about the relevance of the EUETS to climate. On the one hand, high-emitting sectors have both incentives and means to lobby for the largest possible amount of property rights. On the other, too much property means too little scarcity for the market to work (Pearce, 2005). Only a minority of companies believe that the EUETS will result in any reduction in emissions at all (Energy Risk, 8 July 2004). According to the trading company Syneco, $\mathrm{CO}_{2}$ prices would need to increase by $250 \%$ just to get energy producers in Germany to begin to switch from coal to gas, to say nothing of contributing to genuine innovation or a structural transition toward non-carbon production (Carbon Market Europe, 2005; cf. Driesen, 2003). Until grants to emitting industry are sharply reduced, pressure to meet Kyoto reduction targets will fall disproportionately on domestic households and the transport and public sectors.

A final sign of the UN's difficulty in disentangling market agents is that it has been forced into pretending it is not dividing up the earth's carbon-cycling capacity into 'assets, commodities or goods for exchange' (UNFCCC, 1999), partly out of fear of raising the hackles of Southern governments and other critics. The terms 'property' and 'rights' do not appear in official documents produced by the UNFCCC, despite their ubiquity in the tradable permits literature, and are now also avoided, whether out of historical or technical naiveté or a perceived duty to Kyoto, by many of the most prominent independent climate campaigners in large international NGOs.

\section{Failure to Frame Agents under Kyoto's Second Prong}

Kyoto's market requires that the owners not only of existing, but also of new carbon dumps be identified: those who encourage tree growth, manage plantations, become more energy-efficient, stop ploughing soil, switch from coal to gas, and so on. Defining the boundaries of these agents, however, has also proved difficult.

First, eager to prevent industrialized countries from using regrowth of their forests as an excuse for not reducing industrial emissions, the EU and some Southern countries early on demanded that marketable biospheric carbon assets be limited to those resulting from 'direct human-induced' carbon uptake, and not include 'natural fluxes'. Awkwardly, however, this opened up the entire biosphere to carbon property claims, since every part of the globe has been affected by human activity over millennia, from Australia's fire-moulded landscape to North America's forest mosaic (Pyne, 1993; Lovbrand, 2004, p. 453). Moreover, not even the IPCC has been able to factor out 'direct humaninduced' effects from 'indirect human-induced and natural effects' such as those due to enhanced $\mathrm{CO}_{2}$ concentrations and nitrogen deposition: 'the phrase "human-induced" has no scientific meaning' (Watson et al., 2000, pp. 79-80; Houghton, 2001). Hence it is hard to identify what portion of the new carbon dumps should belong to human 
beings at all. The IPCC's suggested way out-to define 'directly human-induced' activities arbitrarily as those resulting from the decisions of contemporary 'land managers', including, most obviously, professional 'afforesters and reforesters', frames agents in a way manageable for a market only by excluding a large overflow of historical actors whose claims it may be difficult ultimately to deny.

Second, in identifying agents who have 'increased energy efficiency' or otherwise 'reduced carbon use', negotiators and their technical advisers have had to suppress the candidacy of actors whose claims happen to be resistant to quantification. Policymakers, environmental movements, indigenous communities who have prevented oil extraction in their territories: all have arguably saved carbon, yet are excluded from selling credits. For instance, after toying with the idea of giving carbon credit for good conservationist policies, the IPCC's panel on land use decided that since 'quantifying the impact of policies themselves is unlikely to be feasible', the focus should be on how much carbon is taken up in specific projects—even though the emissions baselines of those projects will vary under different policies.

Hence it is developers of and investors in specific, more sharply-delineated, ostensibly 'measurable', and usually industrial carbon-saving projects who tend to be designated as the new market's buyers and sellers. These are mainly wealthy corporations. Part of the 'overflow' in this case of framing is likely to be a loss of climatic efficacy, since policy change and political movements are powerful factors in systemic change.

Conflicts over the framing of agents are also emerging at other levels. In New Zealand, plantation owners joined battle with the government in 2003 over who owns the carbon in 200,000 hectares of trees planted after 1989, which are eligible to earn emissions credits under the Kyoto Protocol. The owners claimed the government was trying to steal NZ $\$ 2.6$ billion from them with a stroke of the pen, "possibly the largest private property theft in New Zealand's history' [Business Today (New Zealand), 30 December 2003].

Growing social conflict over new carbon dump sites adds further complications to the struggle to frame calculable agents for the new market. Both types of speculative new carbon dump are likely to magnify existing North-South inequalities. Large emitters, roughly speaking, generally find themselves having to build their new carbon dumps on someone else's land or in someone else's future. Resistance to the idea that they own them is inevitable.

Here, as elsewhere, the 'theoretical' difficulties that experts encounter in attempting to format market agents can't be easily separated from the seemingly more 'physical' opposition of groups affected by attempts to set up a Kyoto market (see 'Three Cases', below). Indeed, knowledge about who is responsible for carbon savings emerges in part from the struggles of groups disadvantaged by attempts to construct a new carbon economy.

\section{Failure to Frame a Hybrid Biospheric/Fossil Commodity}

Even more strikingly, Kyoto's authors have proceeded as if they were in a position to develop quantification and commensuration instruments capable of supporting a 'system of credits and debits wherein emission or sequestration of carbon in the biosphere is equated with emission of carbon from fossil fuels' (Marland et al., 2003, p. 150; cf. Cole, 2002, pp. 67-84). 
The first metrological task needed to make a Kyoto market relevant to climate is to quantify industrial emissions. There is some hope that this task might eventually be achieved, although it is more difficult than simply measuring flows of fossil carbon out of underground deposits, industrial releases of non- $\mathrm{CO}_{2}$ greenhouse gases, or sulphur dioxide emissions. But for the purpose of detecting the comparatively tiny reduction signal needed to demonstrate compliance with Kyoto, current measuring systems are inadequate. Uncertainties of national greenhouse gas emissions of the total energy system 'are in the range of plus or minus 10-30 per cent' (Obersteiner et al., 2002, p. 542).

More serious are the challenges thrown up by the 'political requirement' to 'determine the long-term fate of carbon stored in biomass and soils' (Lovbrand, 2004, p. 452) and to commensurate it with underground fossil carbon: that is, to show that a world which closes a certain number of fossil fuel mines will be climatically equivalent to one which keeps them open but plants more trees, ploughs less soil, fertilizes oceans with iron, and so forth.

The problem here is that above-ground and below-ground carbon are different. To sequester carbon means to set it aside or separate it-in this case, to separate it from the atmosphere. But there are many degrees of separation. The carbon in a cigarette, in the fluid in a lighter, in grass or a tree trunk, in furniture or paper, in the top seven inches of soil, in coal deposits a kilometre underground, in carbonate rock dozens of kilometres beneath the surface-all are separated from the atmosphere, but in different ways, to different degrees and for different average time periods.

Of course, it has always been acknowledged that carbon accounting needs 'to be different for fossil-fuel and biosphere-based emissions' (Kirschbaum and Cowie, 2004, p. 417). Fossil carbon flows into the biosphere/atmosphere system are essentially irreversible over non-geological time periods, while those from the atmosphere into the biosphere are easily reversible and not so easily controlled. It is vastly easier, moreover, to keep accounts of carbon kept safely underground in fossil deposits than to tally up how much is being sequestered in a forestry project and then subtract the amount 'leaking' over project boundaries (through fires, soil erosion, fossil emissions from transport required for the project, evictions leading to forest encroachment elsewhere, etc.). But it has been hoped that fossil emissions and biospheric sequestration can be commensurated through various fudge factors, including applying discounting formulas to sequestration credits based on how long trees survive, making sequestration credits temporary or available only for rental, and so forth. Means have also been suggested for identifying and quantifying all relevant 'leakage' from carbon projects (this official UN term is significant, since it assumes, as Callon would remind us, that a situation obtains in which 'framing' is the norm and overflows are just incidental 'leaks').

None of these methods work, however. Straightforward inadequacy of data is one obstacle. According to one study, for example, mean net Russian carbon balance in 1990 can be pinned down only to the range of -155 to $+1,209$ million tonnes per year. This swamps probable changes in total Russian carbon flux balance between 1990 and 2010, which are expected to be only 142-371 million tonnes, making the figures useless for verifying compliance with the Kyoto Protocol (Nilsson et al., 2000) (see Figure 1). The fact that knowledge of carbon flows among the atmosphere, biosphere and lithosphere is inadequate 'to form the basis for ... any viable trading scheme' is alone sufficient to make the Kyoto Protocol 'completely unverifiable' (Nilsson, 2000, p. 1).

Worse, usable estimates of the degree to which carbon sinks projects are climatically effective are rendered impossible by both conditions of uncertainty (in which not all 


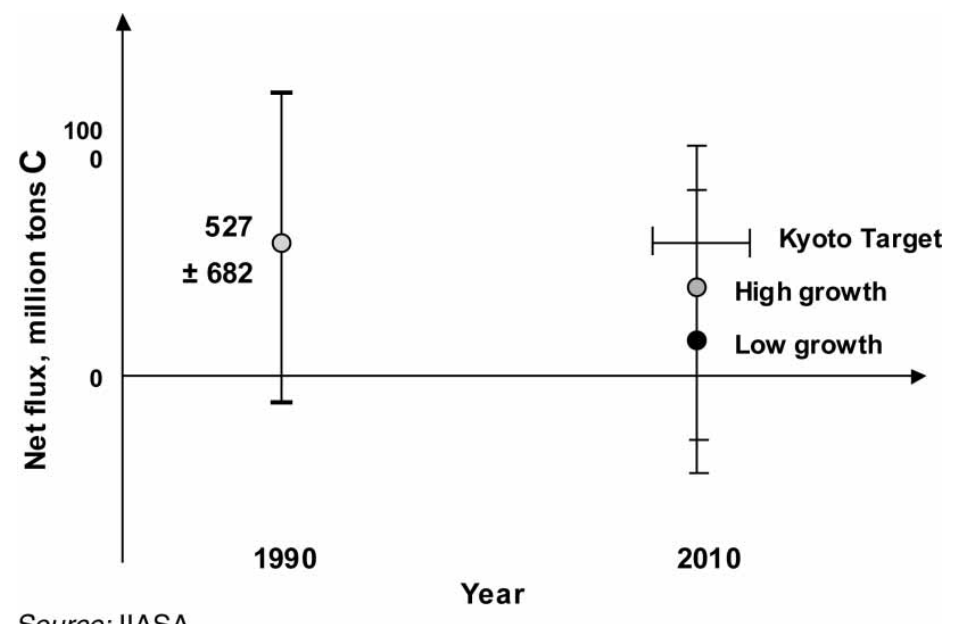

Figure 1.

the probabilities of various possible atmospheric outcomes of sink establishment are known) and conditions of ignorance (in which not even all the possible outcomes themselves are known) (Harremoes et al., 2002). The past two decades of research have continually uncovered hitherto unsuspected variables bearing on the response of ecosystems to climate change and vice versa, as well as surprises about the complexity and nonlinearity of relations between the two, and there is no reason to expect these discoveries to stop. Examples include revelations about the albedo effects of plantations on climate (Betts, 2000), the unpredictability of climatic 'tipping events', nonlinearity of soils' or forests' ability to function as sinks under different conditions (Gill et al., 2002), among many others (German Advisory Council, 1998; Falkowski et al., 2000; Tenner, 2000; Houghton, 2001; Read et al., 2001; Victor, 2001; Pan et al., 2004; Schelhaas et al., 2004; Canadell et al., 2004; Boyd et al., 2004; Stainforth et al., 2005; Knorr et al., 2005; Manley et al., 2005; Jonas et al., 1999; Lohmann, 2001). Issues of commensuration aside, carbon stores in living biomass (with 600-1,000 billion tonnes of carbon) could never be able to be expanded enough to absorb more than a small fraction of remaining fossil fuels (over 4,150 billion tonnes) (Falkowski et al., 2000). The Intergovernmental Panel on Climate Change and the parties to the UNFCCC have so far ignored these realities, assuming without evidence that emissions and 'removals by sinks' can be aggregated quantitatively.

More daunting still for the market project, setting up a measurable equivalence among emissions and biological sequestration would require quantification of the effects of social actions and institutions that mediate carbon flows. Carbon transferred from underground to the atmosphere enters not only the biosphere but also social and cultural spheres. Physical actions (for instance, planting biomass for power plants) bring about social effects (for example, resistance among local farmers, diminished interest in energy efficiency among investors or consumers, loss of local power or knowledge), which in turn bring about further physical effects (for instance, migration to cities, increased use of fossil fuels) with carbon or climatic implications. Calculating 
how much carbon a new tree plantation actually 'offsets', for example, would require estimating how much the plantation has delayed the adoption of a technologically different energy-generation path on the part of carbon credit buyers, observing the 'carbon behaviour' of farmers evicted from the plantation site and their descendents for approximately a century, and so forth. No basis exists in either physical or social science for deriving numbers for the effects on carbon stocks and flows of such social actions (Lohmann, 2001).

\section{Failure to Frame a Hybrid Commodity Including Credits from Clean Development Mechanism (CDM) Projects}

In all the excitement over the imminent arrival of a fully-fledged carbon market, we may be losing sight of one fundamental question-what, exactly, are we trading in? (Environmental Data Services Report, 2004b).

In addition to the carbon emitted by fossil fuel burning and absorbed by the biosphere in the North, the Kyoto Protocol's proposed hybrid commodity encompasses carbon managed by speculative climate change mitigation projects sited in countries not subject to the Kyoto 'cap'. As mentioned above, these projects are being carried out under Kyoto's Clean Development Mechanism (CDM).

UN literature routinely refers to the product to be delivered by all such projects (which include gas capture schemes, dams, tree plantations, efficiency improvements, renewable energy projects, and so on) as 'emissions reductions'. This gives the impression that this product is both unitary and of a calculable piece with what comes out of smokestacks and exhaust pipes. Undermining this assumption, as argued above, is the impossibility of quantifying the social actions that mediate the carbon flows associated with such projects, as well as, in the case of biological projects, the incommensurability, for purposes of verifiable climate mitigation, of underground fossil carbon and active-pool or above-ground carbon.

But such projects' capacity to 'compensate' for industrial emissions is also unverifiable for another reason. This is that their carbon 'savings' can only be calculated by showing how much less greenhouse gas is entering the atmosphere as a result of their presence than would have been the case otherwise. The emissions associated with each with-project scenario must be subtracted from the emissions associated with a unique, otherwise identical, business-as-usual storyline.

The calculational imperatives of the market, in other words, dictate that the counterfactual without-project scenario be presented not as indeterminate and dependent on political choice-that is, as many proponents themselves frankly acknowledge, as something which 'cannot be measured' (Fischer, 2005, p. 1807)—but as singular, determinate and a matter for economic and technical prediction. The inclusion of such projects in a climate market inevitably reduces 'social conditionalities ... that do not easily lend themselves to prediction ... (inter alia, socio-economic development, demographic trends, future land use practices, international policy making) ... to technical and methodological uncertainties' (Lovbrand, 2004, p. 451) or even mere imprecision or data gaps.

In addition to being a logical cul-de-sac, this exercise of building a singular, calculable scenario around 'what would have happened' in the absence of each of dozens of particular carbon projects hampers thinking about broader social and industrial change. 
While understanding what 'could have happened' in the absence of each particular project does mean funnelling intellectual effort into speculation about hypothetical worlds, the hypothetical worlds that are relevant to determining 'what would have happened' without any particular project will all necessarily closely resemble the world with the project (Honore, 1964). To use David Lewis's phrase, getting a better understanding of what could have happened in such circumstances requires 'wiggling the events' (Lewis, 1973) but not shaking them too hard, excluding consideration of scenarios of structural change and sweeping innovation from the start. The opportunity cost of this restriction would itself (impossibly) have to be quantified in any rationally-constructed climate mitigation market.

The attempt to isolate and quantify unique counterfactual baseline scenarios generates so many scientific, cultural and political overflows that it is slowly disintegrating what confidence remains in the CDM's putative product. First, it saddles project validators with the unsustainable claim that they can 'decide' the future. It also burdens them with the claim that conflicts over their counterfactual scenarios, and thus over how 'large' each new carbon dump is, are due merely to mistakes in technique.

On one level, these developments may seem to boost experts' power. They appear, at least temporarily, to give scientific results a 'disproportional influence over social decision-making', allowing decision-makers to 'neutralise and hence legitimise politically charged decisions' undertaken in the absence of public debate (Lovbrand, 2004, p. 451). They also promise to generate indefinite new investment in centres of calculation, since the objective being pursued is unattainable and could in theory absorb any amount of expert effort.

But on another level, the project of trying to isolate and quantify unique counterfactual baselines has led to widespread conflict and finger-pointing within communities of experts themselves. DuPont, for example, has accused its rival Ineos Fluor of overstating emissions 'reductions' from abatement projects (using a methodology already approved by the CDM Executive Board) by a factor of three due to inflation of baselines. Experts' counterfactual scenario-building is likely to be seen at the grassroots as merely a game (see 'Three Cases', below).

A second difficulty with baseline accounting is that it treats carbon project sponsors and managers as free agents while implicitly demoting other actors into passive objects of deterministic calculation. Carbon credits go to well-financed, high-emitting operations capable of hiring professional validators of counterfactual scenarios but not to nonprofessional actors in already low-emitting contexts or social movements actively working to reduce use of fossil fuels. Hence this part of the Kyoto market is likely to generate large climatic 'opportunity costs'.

Third, baseline accounting procedures set up perverse incentives for proponents of new carbon dumps (including host governments, credit buyers and consultant validators seeking future contracts alike) both to postulate and to bring about 'business as usual' scenarios which are the highest-emitting possible, in order to make the proposed projects appear to be saving as much carbon as possible. With a bit of judicious accounting, a company investing in foreign 'carbon-saving' projects can increase fossil emissions both at home and abroad while claiming to reduce them (Lazarus, 2003). In one Latin American country, consultants tippexed out the name of a hydroelectric dam from a copy of a national development plan in an attempt to show that the dam was not already planned or 'business as usual' and therefore was deserving of carbon finance. 
Throughout the South, the CDM is creating incentives for emissions-related environmental laws not to be enforced, since the greater the 'baseline' emissions, the greater the payoffs that can be derived from CDM projects. The calculational machinery that would be necessary for a market in CDM credits, in other words, is itself undermining predictability and the possibility of market calculation.

World Bank officials, accounting firms such as PriceWaterhouseCoopers, financial analysts and a growing number of businesses admit, whether privately or publicly, that no ways exist to demonstrate that carbon finance is what made a project possible. To try to do so, one banker complains, forces investors to lie: 'they have to tell their financial backers that the projects are going to make lots of money, but ... tell the [UN] that they wouldn't be financially viable' without carbon subsidies (Financial Times, 16 February 2005). In announcing its withdrawal from CDM projects in 2004, Holcim Cement went as far as saying that CDM carbon-accounting methodology 'will create other Enrons and Arthur Andersens' (vanderBorght, 2004). Despite such warning signs, consultancies, UN bodies and technocratic NGOs such as the World Resources Institute are continuing relentlessly to try to develop techniques for isolating unique, quantifiable counterfactual baselines.

The last two sections have presented numerous arguments showing why the putative commodity to be produced by CDM and similar 'carbon-saving' programmes cannot be correctly referred to as 'emission reductions', 'carbon', 'carbon dioxide equivalent', or any other entity whose contribution either to climate stabilization or to meeting targets for reducing transfer of fossil carbon to the atmosphere can be measured. Unlike conventional dumps receiving industrial waste, mine tailings, or nuclear materials, the purported new carbon dumps supposedly to be carved out of the biosphere or the future cannot be verified to have anything to sell, or, indeed, to be dumps at all. The next section will make more concrete the CDM's difficulties in disentangling agency and commodity by presenting examples of its search for greenfield dumping sites for fossil-origin carbon and its associated attempt to exercise new forms of globalized control over local land, water, soils, forests and air and the people who depend directly on them.

\section{Three Cases}

At many of the new carbon dump sites, an attempted technical fix for a problem associated with global inequality of access to one capacity is resulting in reduplicated and reinforced inequality of access to other goods at the local level. The outcome is resistance not directly to appropriation of global carbon-cycling capacity, but to intensified enclosure of local futures and of local land, air, water or biodiversity. This opposition-in fruitful combination with professionals' internal conflicts in offices and conference centres-has often slowed project development.

This section will look briefly at cases of carbon dump establishment, resistance and repression on three different continents. It aims to illustrate how the new market's circuits of power link (for example) environmental consultancies in the UK to the drying of wells in Minas Gerais; carbon dioxide emissions from power stations in The Netherlands to hydrogen sulphide releases from a landfill in Durban; and lobbying at climate conferences in Marrakech or Bonn to the hiring of local gunmen in southern Thailand. 


\section{Minas Gerais, Brazil}

In Minas Gerais, a corporation called Plantar S.A. has attempted to secure carbon finance for not switching its pig iron operations from eucalyptus fuel to (more carbon-intensive) coal or coke, as well as for 23,100 hectares of monoculture eucalyptus plantations (World Bank Prototype Carbon Fund, 2002) and for improvements in charcoal production. The scheme is promoted by the Prototype Carbon Fund (PCF) of the World Bank-an institution that, ironically, also provides, in an average year, support for fossil-fuel projects with lifetime emissions of over 1.4 billion tonnes of carbon, or between four and 29 times the amount of annual emissions 'reductions' to be claimed under the CDM (Vallette et al., 2004), and which has approved, since 1992, US\$11 billion in finance for 128 fossil-fuel extraction projects in 45 countries (see Figure 2).

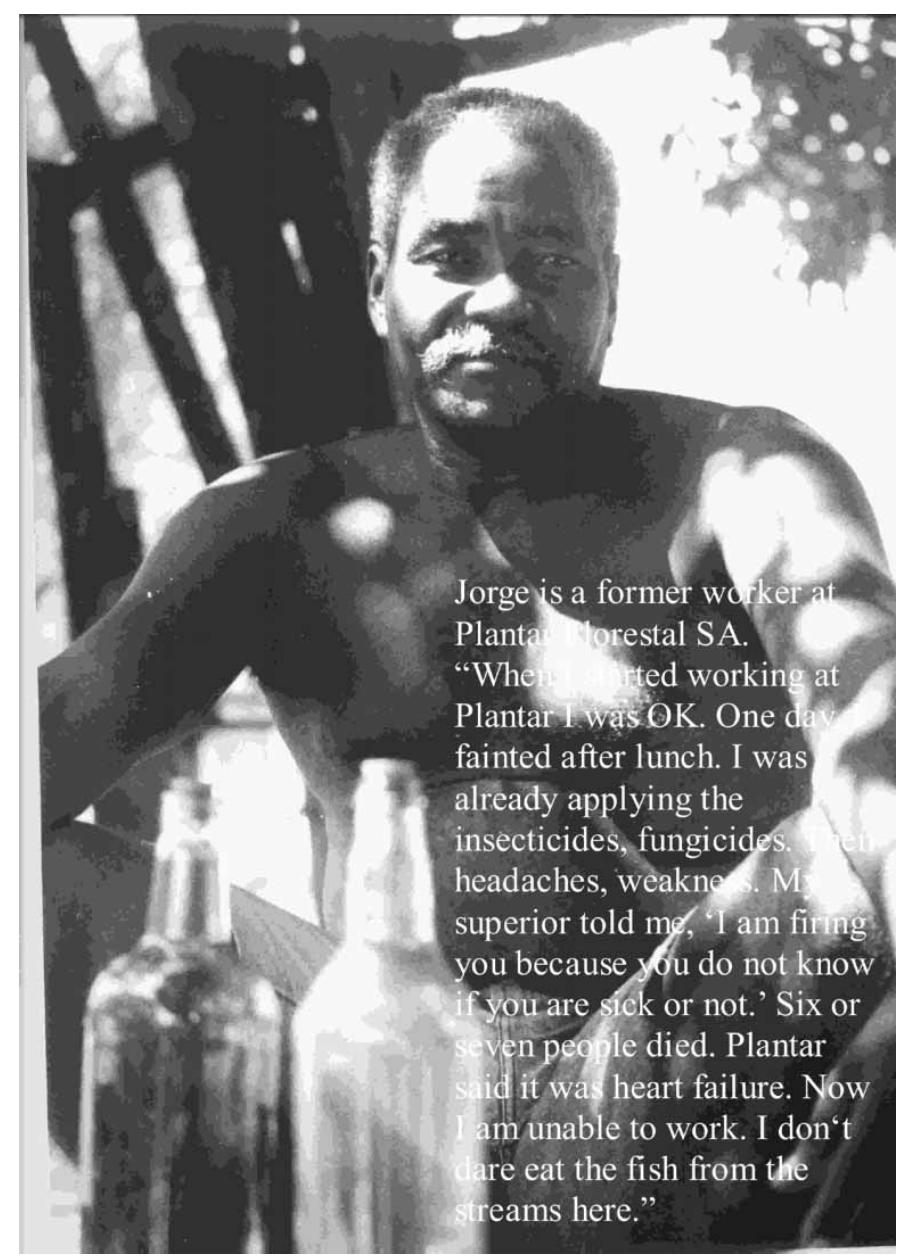

Figure 2. Jorge, a former worker at Plantar, disabled following pesticide exposure. Credit: Tamra Gibertson. 
When proposed, the Plantar project caught many local people off guard. 'We were surprised and bewildered by the news', a group of over 50 trade unions, churches, local deputies, academics, human and land rights organizations and others protested in a letter of 26 March 2003:

Corporations like Plantar S.A. installed themselves in our states in the 1960s and 1970s during the military dictatorship, taking advantage of attractive tax incentives. Local communities were never consulted ... Indigenous peoples ... Afro-Brazilian communities and tens of thousands of [other] peasants . . lost their lands . . . increasing unemployment. ... the new Plantar nursery ..., about which no local inhabitant was consulted ..., diverted an existing road that has always been utilized by local communities, and extended the travelling distance for local inhabitants by more than five kilometers. ... Most lands owned by these corporations are devolutas, ... without land titles, ... [and] belong to the state. According to Brazilian law, corporations cannot acquire this type of land, only peasants. Even so, with often fraudulent registrations in the registry offices and 'hiring' contracts with the state, the corporations succeeded in acquiring hundreds of thousands of hectares of devolutas lands. . . the occupation of [savannah] cerrado areas ... made more difficult the subsistence of these people, which was based on the immense biodiversity of the cerrado. The short-cycle eucalyptus monoculture does not allow any other plant or any animal or bird to live within it, and therefore does not possess any biodiversity ... food products factories closed ... The pig iron companies still use around 15-20 per cent native cerrado vegetation. ... Plantar does not do anything for its former workers, many of whom are injured or suffering from health problems; many have already died as a result of the very bad working conditions associated with charcoal production and eucalyptus cultivation. Eucalyptus plantations result in less jobs if compared with any other agricultural activity (FASE et al., 2003a).

Local residents oppose not only Plantar's continued appropriation of cerrado, farmlands and water for a carbon dump, but also its appropriation of their future:

The argument that producing pig iron from charcoal is less bad than producing it from coal is a sinister strategy. ... What about the emissions that still happen in the pig iron industry, burning charcoal? What we really need are investments in clean energies that at the same time contribute to the cultural, social and economic well-being of local populations. ... We can never accept the argument that one activity is less worse [sic] than another one to justify the serious negative impacts that Plantar and its activities have caused.... [W] want to prevent these impacts and construct a society with an economic policy that includes every man and woman, preserving and recovering our environment (FASE et al., 2003b).

Locals note further that physical intimidation by Plantar, which makes many local residents afraid to let interviewers cite their names, is nowhere acknowledged in project documents. Thwarted by the PCF, the local movement has subsequently appealed directly to European investors not to put money into the Plantar carbon project, with two representatives travelling to Cologne to intervene in the Carbon Expo trade fair held there in July 2004. 
Some 143 local groups and individuals meanwhile stated in a letter to the CDM Executive Board of June 2004 that

the claim that without carbon credits Plantar ... would have switched to coal as an energy source is absurd. ... Yet now [Plantar] is using this threat to claim carbon credits for continuing to do what they have been doing for decades-plant unsustainable eucalyptus plantations for charcoal ... It is comparable to loggers demanding money, otherwise they will cut down trees ... [the CDM] should not be allowed to be used by the tree plantation industry to help finance its unsustainable practices (Suptitz et al., 2004).

In denying the plausibility of Plantar's counterfactual scenario (a switch to coal), project opponents need not be read as asserting that there is a single 'correct' counterfactual alternative (that is, that CDM accounting is possible but just happens to have been performed incorrectly in this case). In context, they are more reasonably read as reaffirming the indeterminacy and political basis of all such counterfactual claims. For them, the economistic misrecognition of decision as prediction is inextricable from environmental threats and physical repression of alternative land uses. To attempt to repress knowledge of the plurality of alternative futures is to attempt to repress popular participation in the taking of alternative decisions.

Indeed, in Brazil it turned out that the repressed returned simultaneously as grassroots resistance and as 'technical' contradiction: in May 2003, the CDM Methodologies Panel rejected the claim of another 'avoided fuel switch' carbon project located adjacent to Plantar's that it was an improvement on 'business as usual'. In November 2003, faced with a resubmitted accounting methodology, the Panel went on to express concern that assertions that carbon-saving projects that merely continue current practice are 'additional' throw up technical problems of 'moral hazard' (UNFCCC, 2003).

\section{Durban, South Africa}

Durban Solid Waste (DSW), part of Durban's city council bureaucracy, manages a landfill site called the Bisasar Road dump. The dump is located in an area designated for people of Indian descent under apartheid's Group Areas Act and is also a primary source of livelihood for the local, mainly 'African', Kennedy Road settlement, many of whose residents recycle materials from the dump (see Figure 3).

Although the site is licensed only to receive domestic waste, medical waste, sewage sludge, private corporate waste and large shipments of rotten eggs have also wound up there. Cadmium and lead emissions are over legal limits, with limits for suspended particulate matter also often exceeded. Concentrations of methane, other organic and inorganic compounds including benzene and toluene, trichloroethylene and formaldehyde are high. Local residents report many health problems, with seven out of ten of the houses in one downwind block on the nearby Clare Estate reporting tumour cases, although these could also be due to incineration practices which stopped in 1997 or to other causes. Some houses are only 20 metres away from the site boundary. When, in 1996, the city council reneged a second time on a 1987 promise to close the site and turn it into sports fields, picnic areas and play areas for children, 6,000 local residents signed a petition of protest, with many blocking the dump site entrance and staging demonstrations and marches. 


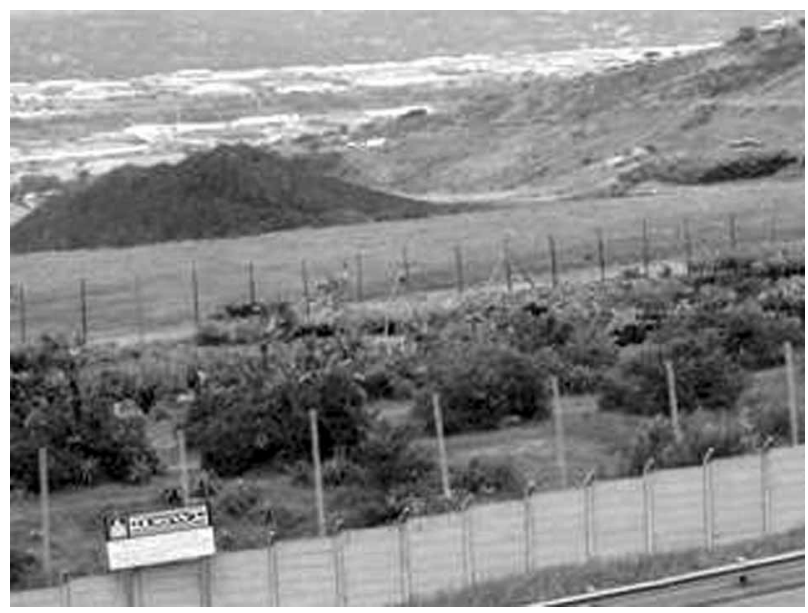

Figure 3. Bisasar Road dump, Durban. Credit: Trusha Reddy.

In 2002, the Prototype Carbon Fund threw a lifeline to what it came to call an 'environmentally progressive ... world-class site' in the form of support for a project to extract methane from the landfill and use it to generate up to 45 megawatts of electricity for supply to the national grid. Two individuals-Sandra Greiner and Robert Chronowski at the PCF in Washington-certified that this electricity would 'replace' electricity which cannot be foregone and which otherwise could have been generated 'only' by burning coal (World Bank, 2003). [Without the US\$15 million provided by the deal, Durban officials said, they would not bother trying to recover the methane as fuel, since the electricity generated in the process costs so much more per kilowatt hour than the local power utility charges for its coal-fired power (Reddy, 2005).] Accordingly, PCF investors-including British Petroleum, Mitsubishi, Deutsche Bank, Tokyo Electric Power and Gaz de France, as well as the governments of The Netherlands, Norway, Finland, Canada, Sweden and Japan-are to get pro rata shares of rights to ignore an increment of their obligations under the Kyoto Protocol to reduce their own mining and burning of fossil fuels.

The PCF asserted that improving the 'financial position of DSW' would also benefit local people and send a 'clear signal' to them that 'the environment is a number-one concern in South Africa and is being dealt with in the best way possible'. However, some locals informed of PCF's intervention (public consultation on the PCF's proposal documents was conducted through the Internet, to which only a tiny minority of the Bisasar Road community have access) took a different view. One resident, who was diagnosed in 1996 with cancer, and whose nephew died of leukaemia, had this to say:

To gain the emissions reductions credits they will keep this site open as long as possible. Which means the abuse will continue as long as possible so they can continue getting those emissions reductions credits. To them how much money they can get out of this is more important than what effect it has on our lives (Carbon Trade Watch, 2002). 
As a result of such opposition, backed by sympathizers in a range of countries, the future of the project now looks uncertain, prompting one of the municipality's top managers responsible for the project to fume that because protesters 'can't think globally anymore', the project is 'literally slipping through our fingers' (Reddy, 2005).

Complicating the situation is the fact that most of the 'African' residents of the nearby Kennedy Road settlement also support extending the life of the dump, out of which many make their livelihood. Their stance has been cemented both by promises that the new World Bank carbon project will provide jobs and scholarships for them and by the fact that the better-off Bisasar Road protesters have shown scant sympathy for Kennedy Road residents' land struggles. Also relevant is the fact that the 'consultative exercises' that the World Bank pushed DSW to conduct in Kennedy Road were one of the few times the community had been officially recognized. Kennedy Road activists are no more under any illusions about the simulations and the agenda connected with such exercises than they are in the front lines of international debate over climate change. But, as Raj Patel of the local Centre for Civil Society at the University of KwaZulu-Natal observes, 'when communities have been systematically denied dignity', such 'consultations' may be the only 'substitute for marginalization' available.

A final argument in favour of the Durban carbon scheme is that extracting methane, in addition to preventing quantities of an especially powerful greenhouse gas from being dispersed into the atmosphere, should benefit local air quality. Clean air, however, is a right South Africans are constitutionally guaranteed even in the absence of carbon trading schemes. In a sense, therefore, Kyoto commodity production is here being staked to the non-enforcement of environmental law. DSW, PCF and their consultants are helping to enclose not only local communities' air, but also their future.

\section{Yala, Thailand}

In this province in Thailand's far south, a 22-23 megawatt power plant fuelled by rubberwood waste and sawdust is being developed by a diverse group of companies. Claimed to be capable of 'replacing' grid electricity generated by fossil fuels, the plant is a project of Gulf Electric, an independent power producer 50\% owned by Thailand's Electricity Generating Public Company (EGCO) and 49\% by Japan's Electric Power Development Company (EPDC); Asia Plywood, a Yala rubberwood processor next to one of whose factories the plant would be located; and Det Norske Veritas (DNV), a Norwegian 'risk management' consultancy which hopes to parlay its experience in certifying the credibility of pioneer carbon schemes such as Plantar and Yala into a major share in CDM's future consultancy market (see Figure 4).

In exchange for investment, EPDC-which operates 66 coal-fired and hydropower stations and burned US\$652 million in fossil fuels in 2001 (EPDC, 2002)-would gain so-called Certified Emissions Reductions to help it, and Japan generally, maintain current levels of fossil-fuel combustion. Also improving their climate profile through the scheme would be EGCO, which operates gas-fired power stations (one of them in partnership with UNOCAL, a US multinational fossil-fuel firm that is a member of anti-Kyoto Protocol and climate-sceptic business groups) and Gulf, which saw its proposed 734-megawatt Bo Nok coal-fired power plant on the Gulf of Thailand defeated in March 2003 by overwhelming opposition from local people concerned about pollution and other potentially destructive effects. While project backers had planned the power 


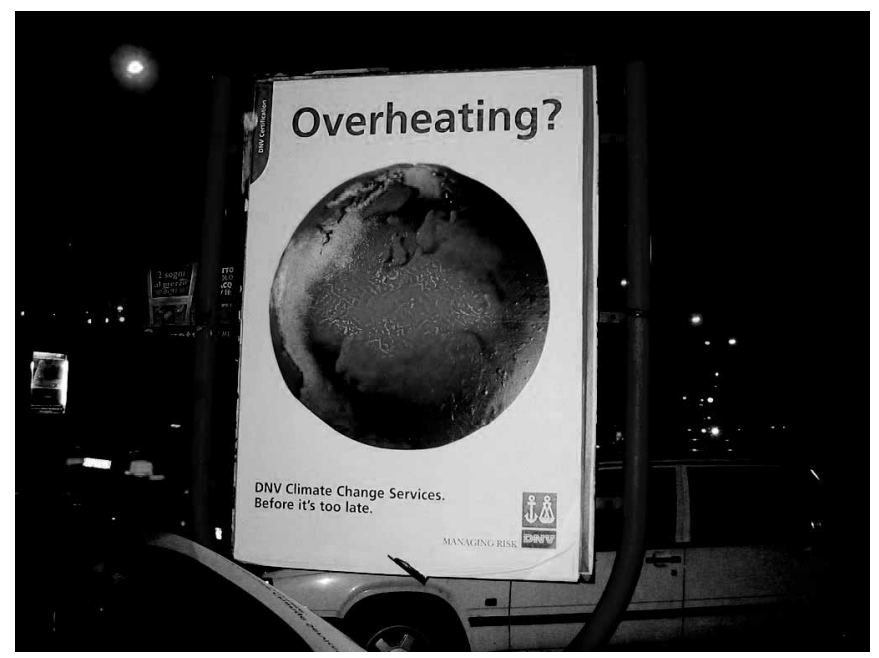

Figure 4. A carbon-dump consultancy company advertisement. Credit: Ponglert Pongwanan.

plant independently of the CDM, they have been interested since at least April 1998, around the height of the Thai financial crisis, in securing supplementary funding through carbon trading (FAO, 2000).

As in the Durban case, most residents of the community adjacent to the site of the proposed project have been unaware of its place in the emerging global carbon trade. As of January 2003, even the local Tambon Administrative Authority (TAO) had yet to receive an environmental impact assessment or other documentation from the firms involved. Yet many residents oppose the project as being likely to reinforce local imbalances of power over air and water quality. Both ordinary villagers and sub-district-level officials feel animosity toward Asia Plywood for causing health and other problems through smoke and ash pollution of local air, water and land, and TAO officials also allege that the firm has not paid its full share of taxes.

Unlike the Det Norske Veritas consultancy, and like Bisasar Road residents, residents of the community around the proposed Yala site view their local company as a social and political, not just a narrowly technical, actor. DNV acknowledges that disposal of rubberwood residues at Asia Plywood and other installations is 'one of the most serious environmental problems in the Yala community'. But it sees the CDM project as solving the underlying issue, which it views as technical.

Similarly, DNV claims to perceive opposition to the project as an obstacle resolvable through technical means. The consultancy admits that local residents have suggested that AP solve its existing problems with 'noise, wastewater and solid waste' before attempting anything else, and communicate the details of construction to the community as well as involve it in monitoring. Yet when at an August 1999 public consultation few respondents agreed with the project, DNV put it down to "previous dissatisfaction with the dust caused by AP's operation' and claimed, without providing any evidence, that, following the installation of a new boiler which uses sawdust, 'Lam Mai [sub-district] residents no longer disagree with the Project' (EPDC, 2002). Local residents, on the other hand, refuse to abstract from the local political context. Viewing corporate reliability 
as a more realistic guide to environmental improvement, they see technical factors such as new boilers or CDM certification as irrelevant as long as underlying conflicts between company and community are not tackled. 'If current problems are not solved', one local health official interviewed asked, 'how are new problems going to be addressed?' Professing 'no trust' in AP, most residents near its factory quietly oppose new development on the Yala site.

By the same token, DNV writes in an anodyne, theoretical way about a 'comprehensive public participation program' to 'accurately inform local residents, government officials and other concerned members of the public about the Project and expected impacts' and 'obtain feedback, mainly from the local communities and concerned government agencies, with regard to their opinions and concerns about the Project', including the TAO committee and residents in 'surrounding villages' (a meeting of less than one hour is recorded with the Lam Mai TAO). The picture is of a project and its participant firms as black box or neutral machine into which formulas for environmental improvement, participation and good community relations can be fed, with near-automatic results.

To local residents, on the other hand, the contents of the black box are both open to view and of powerful interest. They point out that DNV's 'public participation program', instead of involving dissemination of useful information, has featured expenses-paid tours for local people to biomass power plants in Thailand's central region. Such tours, they claim, have included hotel accommodation, food and free visits for some male participants to local prostitutes, but not any close inspection of the plants in question nor chances to meet local people. Local residents also point to AP's name on a sala that the company gave to a Buddhist temple adjacent to its factory after temple monks complained about pollution-an act incurring powerful reciprocal obligations. Other modes of persuasion have also been used: one elderly resident reported receiving three death threats as a result of voicing criticisms of the AP project.

\section{Retranslating and Re-fixing}

It's a working principle of the Head Bureau that the very possibility of error must be ruled out of account. This ground principle is justified by the consummate organization of the whole authority, and it is necessary if the maximum speed is to be attained ... Is there a Control Authority? There are only control authorities. Frankly it isn't their function to hunt out errors in the vulgar sense, for errors don't happen, and even when once in a while an error does happen, as in your case, who can say finally that it's an error? ('The Superintendent' in Franz Kafka, The Castle).

Much of the evidence this paper has marshalled that conditions are not appropriate for the framing of a climate market is, of course, familiar to market proponents. But they tend to (re)translate this evidence into terms that suggest that attempts at framing can continue through what the World Bank's Prototype Carbon Fund calls 'learning by doing'. What is lost in these translations sets up problems leading to a chain of further translations and fresh difficulties. This dynamic-involving, in a manner of speaking, a continual return of 'repressed' content-results from treating what Callon calls a 'hot' situation as if it were 'cold', and has its own important consequences for science, culture and politics. 
The key translation, crudely speaking, is from unquantifiables into quantifiables. Carbon trading advocate Michael Grubb and colleagues, for example, after conceding the 'impossibility' of measuring or defining the climatic difference between with- and without-project scenarios, quickly reinterpret this indeterminacy as 'uncertainty' and then mere 'difficulty' (Grubb et al., 1999). Another expert, frustrated that a counterfactual emissions baseline 'cannot be measured' and hence that the supposed 'reductions' brought about by carbon projects cannot be estimated or assigned an economic value, goes on to describe a 'policy balance' that 'must be struck between the accuracy of the abatement measures, which are needed to preserve the environmental integrity of the projects, and the efficient performance of the system, which is needed to assure cost-effective and productive investment strategies' (Fischer, 2005, p. 1821). What 'cannot be measured' on one page is translated on the next into a course of action capable of being 'accurate' or 'inaccurate' and thus part of an optimizing calculation. CDM projects' need for a unique counterfactual storyline, meanwhile, is often translated into the more manageable need for a merely 'plausible' one. This pattern of rephrasing indeterminacy in economistic or technical idioms suggesting the possibility of management is repeated hundreds of times throughout the literature:

The question of whether a project leads to 'additional' emissions savings is proving to be a major stumbling block. ... it is inherently impossible to verify what would have happened in the absence of the project. ... even with well-documented projects, the uncertainty in the baseline is at least 45 per cent in either direction. ... this uncertainty must be managed 'by putting in place safeguards and taking a conservative approach' to minimise overestimation of emission savings (ENDS, 2002).

[T] he need for administrative revision and approval of counterfactual emissions baselines increases transaction costs enormously (Ellerman et al., 2000).

One common consequence of the 'transaction costs' euphemism is that effective CDM credits become not impossible to calculate, but merely prohibitively expensive (Michaelowa et al., 2003; Michaelowa and Jotzo, 2005; Fichtner et al., 2003). Particularly threatened, on this view, are CDM projects attempting to compensate for less than 50,000 $\mathrm{tCO}_{2}$-equivalent emissions per year, with transaction costs for some micro-schemes running to a prohibitive several hundred Euros per $\mathrm{tCO}_{2}$ equivalent. The economics thus favour projects least likely to lead to innovation or structural change, such as gascapture add-ons to existing industrial plant or industrial tree plantations. Of all the credits being claimed up to 2012 by $111 \mathrm{CDM}$ projects, most come from a handful of schemes to capture and destroy HFC-23 and $\mathrm{N}_{2} \mathrm{O}$, with renewables making up a declining $10 \%$ of the total (CDM Watch, 2004). For this and other reasons, it is said, the fledgling CDM market would need to be 'distorted' in order to promote the development of renewable energy or efficiency, and thus allow the CDM to live up to its name. Yet that would undermine opposing 'market distortions' that the World Bank and other agencies have set up in order to guarantee bargain CDM credits for carbon-intensive Northern industry.

Hence while the 'transaction costs' translation may appear to leave the door open for further fruitless attempts at technical fixes, and for rallying and recruiting technical troops around untenable projects, in practice it, too, can expose the shaky foundations 
of the CDM credit market, as the 'repressed' content returns in a different form. While the translation may delay the process of loss of confidence in the putative commodity, it also creates space for strategic or face-saving retreats by market proponents, making visible to technocratic minds what might not otherwise be discussed at all.

By the same token, even though 'plausibility' is useless as a criterion for isolating a single business-as-usual scenario, the 'implausibility' of various counterfactual baselines proved to be sufficient ground for the CDM executive board and its methodological panel to reject the accounting methodologies for the bulk of the mitigation projects proposed to it in 2003. For similar reasons, a UK Parliamentary Committee recently lambasted the experimental UK Emissions Trading Scheme, which had paid more than $£ 100$ million to four companies 'for keeping emissions down to levels they had already achieved', as 'bullshit', 'stupid', a 'mockery', and an 'outrageous waste of public money' which undermined government emissions reduction policies (ENDS, 2004a).

In many circumstances, in other words, an attempt to prove that indeterminacy 'cannot' be reinscribed within spaces of market calculation may well be a less effective mode of criticism than simply following out the consequences of that reinscription. After all, the reinscription is being carried out, and in numerous ingenious ways. As Callon (1998a) observes in a witty rewriting of Galileo: Eppure calcolano! And yet they calculate!

In a similar way, carbon technocrats originally tended to deny flatly the need to quantify socially-mediated carbon effects of CDM projects, protesting that the issue was 'not their department' or 'could be ignored'. And when, inevitably, they were forced to take on the question, they attempted to reframe it in anodyne, management-friendly terms:

[S]ubtropical emerging carbon plantation establishment reduces the storage of carbon in temperate forests as timberland management declines in these regions ... relatively small programs ... have effects beyond the scope of the projects considered ... carbon may leak from the system ... policy makers must carefully consider the system-wide impacts of different strategies as they assess the costs ... (Sedjo and Sohngen, 2000).

Only full accounting on project scale ... and on national level, including carbon flows in trade and commerce, can avoid the investment in virtual sinks (Valentini et al., 2000).

Yet even in such translated forms, the contradictions have led to growing scepticism about the practicality of new carbon dump projects.

A second style of technocratic translation attempts to avoid such consequences by treating the climatic efficacy of the CDM commodity as simply irrelevant to its value and the transaction costs of 'verification' as a nuisance (Cameron, 2005; Financial Times, 16 February 2005). In 2000, for instance, two experts proposed referring the question of 'what would have happened without a project' to frankly arbitrary decision by a committee (Yamin and Haites, 2000). Two years later, developers, brokers, Northern government ministers, the World Bank and others frustrated by slow market development tried briefly to float the idea that CDM projects did not, after all, have to show that they would not have happened without carbon investment (CDM Watch, 2005, p. 22).

This approach, however, faces a dilemma. On the one hand, it can concede that the good to be traded is not 'carbon' or 'emissions reductions'. The problem with this is that it 
immediately makes the putative commodity (whatever it is) unattractive to many buyers and reopens wrangles about what the Kyoto Protocol is for. On the other hand, it can be insisted that the commodity is somehow after all indeed 'carbon' or 'emissions reductions' even though the whole idea of verification is disdained. In that case, the outcome is likely to be what the orthodox economics profession describes as a selfdestructing 'lemons market' (Akerlof, 1970; Obersteiner et al., 2000), in which buyers can neither locate nor create demand for any existing quality products.

A third, more optimistic technocratic translation maintains that there ought to exist an optimal way of trading off environmental efficacy against low transaction costs (of verification), so that some climate effectiveness can be bought in a CDM market, but at not too high a price. This approach, however, has the disadvantage that it eventually collapses into one of the first two translations.

For example, technocrats frustrated by the 'high transaction costs, numbers of participants and uneven information distribution' (Fischer, 2005) involved in manufacturing plausible, quantifiable counterfactual scenarios have often been tempted to compromise by appealing to generic criteria which can be used to quantify the degree to which a whole range of projects, considered as a whole, are better than 'business as usual'. Yet here, too, the repressed inevitably returns. It rapidly becomes evident that such generic criteria, even on economistic assumptions, let in floods of 'free-rider' credits for companies seeking subsidies for their existing operations, requiring further attempts at translation or repression (Bernow et al., 2000). Saving on transaction costs by standardization, specialist outsourcing or skimping on verification efforts meets a similar fate. Once again, the Kyoto Protocol's attempt to fulfil the dream of its Chicago economist great-grandfather, Ronald Coase-among whose watchwords were simplicity and pragmatism - has ironically wound up uncorking an unstoppable fount of complexity far beyond anything he feared might result from pollution taxes.

\section{Conclusion}

Although the Kyoto Protocol has failed to garner the support of the government of the country, the US, by and for whom it was largely made, environmentalists, politicians and journalists elsewhere have been nearly unanimous in promoting it as a necessary 'first step' toward more serious efforts to address climate change. The metaphor is linear, even arithmetical: before the necessary $60-80 \%$ reductions must come 5\% reductions, and so on. The market Kyoto attempts to set up is seen merely as an incidental collection of 'flexible mechanisms' that will make it possible to attain this extrinsic numerical goal more efficiently. 'Support for Kyoto has become a litmus test for determining those who take the threat of climate change seriously', while the voices of the small if diverse groupings who are both convinced of the urgency of the climate crisis and critical of Kyoto have 'largely gone unheard' (Rayner, 2005).

This article has argued that, viewed in a perspective informed by science and technology studies, things are not as simple as this 'first step' linear metaphor suggests. What with its loopholes, its unverifiability, and its inattention to incentives for structural change, the Kyoto Protocol appears incapable of checking the upward flow of fossil carbon into the overflowing above-ground carbon dump. The move to secure this dump for industrialized country governments and heavily-polluting private sector actors by formalizing quasiprivate property rights in a previously less structured 'open access' regime is confused, 
regressive and divisive. Also fraught with difficulties is Kyoto's attempt to locate or develop new carbon dumps capable of delaying reductions in the overall amount of dumping rights on offer and then to make them available for sale to major emitters.

In particular, the market ideology-driven attempt to synthesize a hybrid Kyoto commodity is squandering science and technology on a huge set of scientifically- and technologically-impossible programmes, procedures and projects. So outlandish, dynamic, widespread and structural is the resulting cascade of falsehoods and failures that it seems inappropriate to describe it as a simple collection of 'errors'. The term 'scientific fraud'-typically associated with the misadventures of a Trofim Lysenko or a Cyril Burt-is also too weak and limited to encompass events since the 1990s. As with Third World development (Ferguson, 1990) or prison reform (Foucault, 1976), a great deal more is at work.

To explain the persistence of the Kyoto 'technical fix' (a fix that does not fix), it is perhaps first necessary, as this article has suggested, to grasp the growing extent to which the imaginations of political activists, physical scientists and technocrats alike have been captured and constrained by 'free market' ideology in a pervasive context of privatization, corporatized science, and domination by experts. Caught between the Kafkaesque logic of the carbon technocracy and the debunking attitude of its opponents at the grassroots, many concerned intellectuals and climate activists have become more credulous than either.

On a deeper level, it is useful to look past the 'failure' (in climate mitigation terms) of the attempt to create and market Kyoto's hybrid commodity and toward the 'successes' of Kyoto accounting methods and other technical institutions in creating new cultural and political tools for marginalizing certain types of futures and actors. First, as argued above, the institutions surrounding the new carbon market succeed in diverting financial and intellectual resources away from political actions and technological innovations that could stem the flow of fossil carbon from below- to above-ground. Instead they add what one former World Bank specialist acknowledges to be 'epicycles' (such as the $\mathrm{CDM}$ ) to an anachronistic, overwhelmingly fossil-centred system. World Bank loans exacerbating climate change, for example, exceed grants that claim to 'ameliorate' it by a ratio of at least 17:1 (Vallette et al., 2004). Second, the theory and practice of 'national allowances' succeed in reducing the space available for popular movements to discuss alternatives to the way that property in the global carbon dump is being created and inequitably distributed. Third, baseline-and-credit accounting carried out by a narrow professional class succeeds in sidelining the contributions of non-corporate actors as well as discussion and other actions directed toward alternative futures.

For these and other reasons, tradable permit and credit approaches to climate change, whatever the contradictions they engender or the resistance they provoke, are likely to remain attractive to many powerful sectors in society and the intellectuals who work in and for them. This is why the way forward cannot be confined to exposing 'scientific' mistakes and contradictions, but will have to understand and deal with their roots and consequences as part of a broader political movement.

\section{Acknowledgements}

Material from this article has been presented at academic conferences at Chiang Mai, Ohio State and Yale universities as well as environmentalist, UN-associated or other meetings 
in Bangkok, Bonn, Edinburgh, Espirito Santo, Helsinki, London, Lyons, Manila, New York, Oxford, Porto Alegre, Quito, San Francisco, Sheffield, Stockholm, Stubicke Toplice and Uppsala. The author would like to thank participants at these events for their ideas and criticisms, as well as Jutta Kill, Les Levidow, Raj Patel, Ben Pearson, Sarah Sexton, Nick Hildyard and two anonymous reviewers.

\section{References}

Acheson, J. and McCay, B. (1990) The Question of the Commons (Tucson: University of Arizona Press).

Agarwal, A., Narain, S. and Sharma, A. (1999) Green Politics: Global Environmental Negotiations (New Delhi: Center for Science and the Environment).

Akerlof, G. (1970) The market for 'lemons': qualitative uncertainty and the market mechanism, Quarterly Journal of Economics, 84(3), pp. 488-500.

Barnes, P. (2001) Who Owns the Sky? Our Common Assets and the Future of Capitalism (Washington: Island Press).

Bastianoni, S., Pulselli, F. M. and Tiezzi, E. (2004) The problem of assigning responsibility for greenhouse gas emissions, Ecological Economics, 49(3), pp. 253-257.

Bernow, S., Kartha, S. et al. (2000) Free-Riders and the Clean Development Mechanism (Gland, Switzerland: World Wildlife Fund).

Betts, R. A. (2000) Offset of the potential carbon sink from boreal forestation by decreases in surface albedo, Nature, 408(9 November), pp. 187-190.

Bloomberg News (2004) Chile's agrosuper sells credits from pig waste to utilities, 20 September.

Boyd, P. W., Law, C. S., Wong, C. S. et al. (2004) The decline and fate of an iron-induced subarctic phytoplankton boom, Nature, 428 (1 April), pp. 549-553.

Bromley, D. (1991) Environment and Economy: Property Rights and Public Policy (Oxford: Blackwell).

Buck, S. (1985) No tragedy on the commons, Environmental Ethics, 7(1), pp. 49-61.

Burgess, J., Clark, J. and Harrison, C. M. (1998) Respondents' evaluations of a contingent valuation survey: a case study based on an economic valuation of the wildlife enhancement scheme, Pevensey Levels in East Sussex, Area, 30(1), pp. 19-27.

Callon, M. (1998a) The embeddedness of economic markets in economics, in: M. Callon (Ed.) The Laws of the Markets, pp. 1-57 (Oxford: Blackwell).

Callon, M. (1998b) An essay on framing and overflowing: economic externalities revisited by sociology, in: M. Callon (Ed.) The Laws of the Markets, pp. 244-269 (Oxford: Blackwell).

Callon, M. (1999) Actor network theory: the market test, in: J. Law and J. Hassard (Eds) Actor Network Theory and After, pp. 181-195 (Oxford: Blackwell).

Cameron, J. (2005) Testimony to House of Commons Environmental Audit Committee, in: House of Commons Environmental Audit Committee, The International Challenge of Climate Change: UK Leadership in the G8 and EU. Fourth Report of Session 2004-5 (London: The Stationery Office).

Canadell, J. G., Ciais, P., Cox, P. and Heimann, M. (2004) Quantifying, understanding and managing the carbon cycle in the next decades, Climatic Change, 67(2-3), pp. 147-160.

Carbon Market News (2005) Available at http://www.pointcarbon.com (accessed 7 February, 3 August).

Carbon Market Europe (2005) Available at http://www.pointcarbon.com (accessed 11 February).

Carbon Trade Watch (2002) The Sky's Not the Limit: The Emerging Emissions Trading Markets (Amsterdam: Transnational Institute).

Citigroup Smith Barney (2003) The Impact of Carbon Trading on the European Sector (London), 10 October.

Clean Development Mechanism Watch (CDM Watch) (2004) Market Failure: Why the Clean Development Mechanism Won't Promote Clean Development (Sydney: CDM Watch). Available at www.cdmwatch.org.

Clean Development Mechanism Watch (CDM Watch) (2005) The World Bank and the Carbon Market: Rhetoric and Reality (Sydney: CDM Watch). Available at www.cdmwatch.org.

Climate Neutral Network (2000) Business and the Environment XI (5). Available at http://www.climateneutral. com/press_bus_env.html.

Coase, R. H. (1937) The nature of the firm, Economica, 4.

Coase, R. H. (1960) The problem of social cost, Journal of Law and Economics, 3, pp. 1-44.

Coase, R. H. (1988) The Firm, the Market and the Law (Chicago: University of Chicago Press). 
Cole, D. H. (2002) Pollution and Property: Comparing Ownership Institutions for Environmental Protection (Cambridge: Cambridge University Press).

Collins, H. M. (1992) Changing Order: Replication and Induction in Scientific Practice (Chicago: University of Chicago Press).

Dales, J. H. (1968) Land, water and ownership, Canadian Journal of Economics, November.

Deepak, M. (2005) Leveraging CDM to Mobilize Disaster Relief Funding: It Could Make Good Business Sense (Kolkata).

Department of Environment, Food and Rural Affairs (DEFRA) (2005) EU Emissions Trading Scheme, UK National Allocation Plan, Revised List of Installations and Allocations (London: DEFRA).

Driesen, D. M. (2003) The Economic Dynamics of Environmental Law (Cambridge, MA: Massachusetts Institute of Technology Press).

Dyson, F. J. (1977) Can we control carbon dioxide in the atmosphere?, Energy, 2, pp. 287-291.

Electric Power Company Development (2002) Project Design Document for a Rubber Wood Residue Power Plant in Yala, Thailand (Tokyo: EPCD), August.

Ellerman, A. D., Joskow, P. L. and Harrison, D. (2003) Emissions Trading in the US: Experience, Lessons and Considerations for Greenhouse Gases (Arlington, VA: Pew Center on Global Climate Change).

Ellerman, A. D., Joskow, P. L., Schmalensee, R. et al. (2000) Markets for Clean Air: The US Acid Rain Program (Cambridge: Cambridge University Press).

Environmental Data Services (ENDS) (2002) ENDS Report, 328, May.

Environmental Data Services (ENDS) (2003a) ENDS Report, 341, June.

Environmental Data Services (ENDS) (2003b) ENDS Report, 346, November.

Environmental Data Services (ENDS) (2004a) ENDS Report, 352, May.

Environmental Data Services (ENDS) (2004b) ENDS Report, 354, July.

Falkowski, P., Scholes, R. et al. (2000) The global carbon cycle: a test of our knowledge of Earth as a system, Science, 290 (12 October).

FASE et al. (2003a) Open letter to those responsible for, and investing in, the Prototype Carbon Fund (PCF). Available at http://www.cdmwatch.org (accessed 26 March).

FASE et al. (2003b) Open Letter to Executives and Investors in the PCF (23 May).

Ferguson, J. (1990) The Anti-Politics Machine: Development, Depoliticization and Bureaucratic Power in Lesotho (Cambridge: Cambridge University Press).

Fichtner, W., Graehl, S. and Rentz, O. (2003) The impact of private investors' transaction costs on the cost effectiveness of project-based Kyoto mechanisms, Climate Policy, 3(3), pp. 249-259.

Fischer, C. (2005) Project-based mechanisms for emissions reductions: balancing trade-offs with baselines, Energy Policy, 33(14), pp. 1807-1823.

Fleming, D. (2005) Domestic tradable quotas: a practical policy response to climate change and oil depletion. Available at http://www.dtqs.org.

Food and Agriculture Organization (FAO) Regional Wood Energy Development Programme (2000) Options for Dendropower in Asia: Report on the Expert Consultation, Manila, 1-3 April 1998 (Bangkok: FAO).

Foucault, M. (1976) Discipline and Punish (London: Penguin).

German Advisory Council on Global Change (1998) The Accounting of Biological Sinks and Sources under the Kyoto Protocol-A Step Forwards or Backwards for Global Environmental Protection? (Bremerhaven: GACGC).

Gill, R. A., Polley, H. W., Johnson, H. B., Anderson, L. J., Maherall, H. and Jackson, R. B. (2002) Nonlinear grassland responses to past and future atmospheric $\mathrm{CO}_{2}$, Nature, 417 (16 May), pp. 279-283.

Goffman, E. (1974) Frame Analysis: An Essay on the Organization of Experience (New York: Harper and Row).

Grubb, M., Vrolijk, P. et al. (1999) The Kyoto Protocol: A Guide and Assessment (London: Royal Institute for International Affairs).

Hahn, R. and Stavins, R. (1995) Trading in greenhouse permits: a critical examination of design and implementation issues, in: H. Lee (Ed.) Shaping National Responses to Climate Change (Washington: Island Press).

Harremoes, P., Gee, D. et al. (2002) The Precautionary Principle in the 20th Century: Late Lessons from Early Warnings (London: Earthscan).

Honore, A. M. (1964) Can and can't, Mind, 73(292), pp. 463-479.

Houghton, J. T. (Ed.) (1996) Guidelines for National Greenhouse Gas Inventories (Paris: OECD).

Houghton, R. A. (2001) Counting terrestrial sources and sinks of carbon, Climatic Change, 48, pp. 525-534.

House of Commons Environmental Audit Committee (2005) The International Challenge of Climate Change: UK Leadership in the G8 and EU. Fourth Report of Session 2004-5 (London: The Stationery Office). 
Illich, I. (1983) Gender (New York: Pantheon).

Intergovernmental Panel on Climate Change (1990) First Assessment Report (Cambridge: Cambridge University Press).

International Association for the Study of Common Property (IASCP) (2005) Comprehensive Bibliography of the Commons. Available at http://dlc.dlib.indiana.edu/cpr/index.php.

Jonas, M. et al. (1999) Full Carbon Accounting and the Kyoto Protocol: A Systems-Analytical View, Interim Report IR-99-025 (Laxenburg, Austria: International Institute for Applied Systems Analysis).

Kirschbaum, M. U. F and Cowie, A. L. (2004) Giving credit where credit is due. A practical method to distinguish between human and natural factors in carbon accounting, Climatic Change, 67(2-3), pp. 417-436.

Knorr, W., Prentice, I. C., House, J. I. and Holland, E. A. (2005) Long-term sensitivity of soil carbon turnover to warming, Nature, 433 (20 January), pp. 298-302.

Latour, B. (1999) Pandora's Hope: Essays on the Reality of Science Studies (Cambridge, MA: Harvard University Press).

Lazarus, M. (2003) The CDM quantification challenge: time for a more standardized approach, presentation at World Resources Institute/World Business Council on Sustainable Development, side event at the Ninth Conference of the Parties to the UNFCCC, 10 December, Milan.

Leggett, J. (1999) The Carbon War: Dispatches from the End of the Oil Century (London: Allen Lane).

Lewis, D. (1973) Counterfactuals (Cambridge, MA: Harvard University Press).

Lohmann, L. (1998a) Whose Voice is Speaking? How Opinion Polling and Cost-Benefit Analysis Synthesize New 'Publics' (Sturminster Newton: The Corner House), May. Available at http://www.thecornerhouse. org.uk.

Lohmann, L. (1998b) Missing the Point of Development Talk: Reflections for Activists (Sturminster Newton: The Corner House), August. Available at http:www.thecornerhouse.org.uk.

Lohmann, L. (2000) Review of Zerner, C., ed. (2001) Culture and the Question of Rights. Available at http:www.thecornerhouse.org.uk.

Lohmann, L. (2001) Democracy or Carbocracy? Intellectual Corruption and the Future of the Climate Debate (Sturminster Newton: The Corner House), October. Available at http:www.thecornerhouse.org.uk.

Lovbrand, E. (2004) Bridging political expectations and scientific limitations in climate risk management-on the uncertain effects of international carbon sink policies, Climatic Change, 67(2-3), pp. 449-460.

Manley, J., Van Kooten, G. C., Moeltner, K. and Johnson, D. W. (2005) Creating carbon offsets in agriculture through no-till cultivation: a meta-analysis of costs and carbon benefits, Climatic Change, 68(1-2), pp. 41-65.

Marland, G., Pielke, R. A., Apps, M. et al. (2003) The climatic impacts of land surface change and carbon management, and the implications for climate-change mitigation policy, Climate Policy, 3(2), pp. 149-157.

McCloskey, D. N. (1998) The Rhetoric of Economics (Madison: University of Wisconsin Press).

Michaelowa, A. and Jotzo, F. (2005) Transaction costs, institutional rigidities and the size of the clean development mechanism, Energy Policy, 33(4), pp. 511-523.

Michaelowa, A., Stronzik, Frauke, E. and Hunt, A. (2003) Transaction costs of the Kyoto mechanisms, Climate Policy, 3(2), pp. 261-278.

Mitchell, T. (2002) Rule of Experts: Egypt, Technopolitics, Modernity (Berkeley: University of California Press).

Nilsson, S. (2000) Editorial, Options, International Institute for Applied Systems Analysis (IIASA), Laxenburg, Austria, Autumn.

Nilsson, S., Shvidenko, A. et al. (2000) Full Carbon Account for Russia, IIASA Interim Report IR-00-021 (Laxenburg, Austria: International Institute for Applied Systems Analysis). Available at http:// www.iiasa.ac.at.

Obersteiner, M., Ermoliev, Y., Gluck, M. et al. (2000) Avoiding a Lemons Market by Including Uncertainty in the Kyoto Protocol: Same Mechanism-Improved Rules, IIASA Interim Report IR-00-043 (Laxenburg, Austria: International Institute for Applied Systems Analysis).

Obersteiner, M., Jonas, M. and Nilsson, S. (2002) Quantifying a fully verifiable Kyoto, World Resource Review, 14(4), pp. 542-554.

Oilwatch (2000) Position Paper: Fossil Fuels and Climate Change, The Hague, November.

Ostrom, E. (1990) Governing the Commons: The Evolution of Institutions for Collective Action (Cambridge: Cambridge University Press).

Pan, Y., Luo, T., Birdsey, R., Hom, J. and Melillo, J. (2004) New estimates of carbon storage and sequestration in China's forests: effects of age-class and method on inventory-based carbon estimation, Climatic Change, 67(2-3), pp. 211-236. 
Pearce, F. (2001) Calling the tune, New Scientist, (7 July), pp. 47-49.

Pearce, F. (2005) A most precious commodity, New Scientist, 2481, (8 January), p. 6.

Polanyi, K. (2001 [1944]) The Great Transformation (Boston: Beacon Press).

Pyne, S. (1993) World Fire: The Culture of Fire on Earth (Seattle: University of Washington Press).

Quine, W. V. O. (1960) Word and Object (Cambridge, MA: MIT Press).

Rayner, S. (2005) Testimony to House of Commons Environmental Audit Committee, in: House of Commons Environmental Audit Committee, The International Challenge of Climate Change: UK Leadership in the G8 and EU. Fourth Report of Session 2004-5 (London: The Stationery Office).

Read, D. et al. (2001) The Role of Land Carbon Sinks in Mitigating Global Climate Change (London: The Royal Society).

Reddy, T. (2005) Facing a Double Challenge (Durban: University of KwaZulu-Natal Centre for Civil Society). Available at www.carbontradewatch.org.

Rose, C. M. (1999) Expanding the choices for the global commons: comparing newfangled tradable allowance schemes to old-fashioned common property regimes, Duke Environmental Law and Policy Forum, 45, pp. $45-72$.

Sampson, V. and Lohmann, L. (2000) Genetic Dialectic: The Biological Politics of Genetically Modified Trees (Sturminster Newton: The Corner House), December. Available at http:www.thecornerhouse.org.uk.

Sandor, R. L., Bettelheim, E. C. and Swingland, I. R. (2002) An overview of a free-market approach to climate change and conservation, in: I. R. Swingland (Ed.) Capturing Carbon and Conserving Biodiversity: The Market Approach, pp. 56-69 (London: Earthscan).

Schelhaas, M. J., Nabuurs, G. J., Jans, W. et al. (2004) Closing the carbon budget of a Scots Pine forest in The Netherlands, Climatic Change, 67(2-3), pp. 309-328.

Scott, J. (1999) Seeing like a State: How Certain Schemes to Improve the Human Condition Have Failed (New Haven: Yale University Press).

Sedjo, R. and Sohngen, B. (2000) Forestry Sequestration of $\mathrm{CO}_{2}$ and Markets for Timber (Washington: Resources for the Future), September.

Stainforth, D. A., Aina, T., Christensen, C. et al. (2005) Uncertainty in predictions of the climate response to rising levels of greenhouse gases, Nature, 433 (27 January), pp. 403-407.

Star, L. and Griesemer, J. (1989) Institutional ecology, 'translations' and boundary objects: amateurs and professionals in Berkeley’s Museum of Vertebrate Zoology, 1907-39, Social Studies of Science, 19, pp. 387-420.

Stewart, R. B. (1990) Privprop, regprop, and beyond, Harvard Journal of Law and Public Policy, 13(91, 93).

Suptitz, A. P. L. et al. (2004) Open letter to CDM Executive Board, Minas Gerais, June.

Tenner, C. (2000) Verification of the Kyoto Protocol: A Fundamental Requirement, VERTIC Briefing Paper $00 / 6$, October.

Thomas, N. (1991) Entangled Objects: Exchange, Material Culture and Colonialism in the Pacific (Cambridge, MA: Harvard University Press).

Thompson, E. P. (1990) Customs in Common (New York: New Press).

United Nations (1992) United Nations Framework Convention on Climate Change (New York: United Nations).

United Nations Framework Convention on Climate Change (1999) FCCC/SB/1999/8 (New York: United Nations).

United Nations Framework Convention on Climate Change (2003) Report of the Eighth Meeting of the Methodologies Panel (Bonn: UNFCCC). Available at http://cdm.unfccc.int/Panels/meth/Meth08rep_ext.pdf.

Valentini, R. et al. (2000) Accounting for Carbon Sinks in the Biosphere-European Perspective (Brussels: CarboEurope, European Director General Desk).

Vallette, J., Wysham, D. and Martinez, N. (2004) Wrong Turn from Rio: The World Bank's Road to Climate Catastrophe (Washington: Institute for Policy Studies).

vanderBorght, B. (2004) Assessment of present CDM methodologies, presentation at World Business Council on Sustainable Development, side event at the Tenth Conference of the Parties to the UNFCCC, 10 December, Buenos Aires.

vanderBorght, B. (2004/5) Making performance count, Carbon Finance, 2(1), p. 11.

Vedantam, S. (2005) Kyoto credits system aids the rich, some say, Washington Post, 12 March.

Victor, D. (2001) The Collapse of the Kyoto Protocol and the Struggle to Slow Global Warming (Princeton: Princeton University Press).

Walzer, M. (1983) Spheres of Justice: A Defense of Pluralism and Equality (New York: Basic Books).

Watson, R. T., Noble, I., Bolin, B. et al. (Eds) (2000) Land Use, Land Use Change and Forestry (Cambridge: Cambridge University Press). 
Winichakul, T. (1994) Siam Mapped: A History of the Geo-Body of a Nation (Chiang Mai: Silkworm Books and University of Hawaii Press).

Wittgenstein, L. (1953) Philosophical Investigations (Cambridge: Cambridge University Press).

Wood, E. M. (2002) The Origin of Capitalism: A Longer View (London: Verso).

World Bank Prototype Carbon Fund (2002) Brazil: Sustainable Fuelwood and Charcoal Production for the Pig Iron Industry in Minas Gerais: The 'Plantar' Project, Project Design Document (Washington: World Bank), 14 March.

World Bank Prototype Carbon Fund (2003) Durban, South Africa: Landfill Gas to Electricity, Project Design Document, Final Draft (Washington: World Bank), January.

Yamin, F. and Haites, E. (2000) The clean development mechanism: proposals for its operation and governance, Global Environmental Change, 10(1), pp. 27-45.

Zammit Cutajar, M. (2004) Reflections on the Kyoto Protocol-looking back to see ahead, MS.

Zelizer, V. (1997) The Social Meaning of Money: Pin Money, Pay Checks, Poor Relief and Other Currencies (Princeton: Princeton University Press). 
